\title{
USING TRADITIONAL ECOLOGICAL KNOWLEDGE (TEK) TO ASSIST RESILIENT FOOD PRODUCTION IN THE SOLOMON ISLANDS. A CASE STUDY OF SOLUVE COMMUNITY.
}

\section{Chelcia Gomese}

\author{
A 90pts thesis \\ Submitted to the Victoria University of Wellington \\ in partial fulfilment of requirements for the degree of \\ Masters of Environmental Studies
}

School of Geography, Environment and Earth Sciences Victoria University of Wellington 
This page was intentionally left blank 
This thesis is dedicated to my late mother, Darlene Gomese.

'Because of you, I am able to go to school'

Chelcia 2017 
This page was intentionally left blank 


\section{ACKNOWLEDGEMENTS}

Jeremiah 29:11

\section{For I know the plans I have for you," declares the LORD, "plans to prosper you and not to harm you, plans to give you hope and a future.}

I thank God first, and foremost for the many blessings he has given me this far, and for the way he has led me through my journey here at Victoria University of Wellington. I also want to thank people who have supported me throughout this thesis journey.

- My parents, Gibson Gomese and Darlene Gomese, brothers Larren, and BranskieFor the love and the support and the opportunity to go to school

- Dr Rebecca Kiddle, my supervisor- For her patience and support in writing my entire research thesis and having the idea to do my masters works placement in SPREP.

- NZAID Team (VUW) - For their support in my studies.

- The NZAID Pacific Scholarship Award, my sponsors- For the opportunity to study in this beautiful country and help develop my skills.

- Luamanuvao Winnie Laban (Assistant Vice Chancellor- Pasifika)- For being my inspiration and believing that every Pacific Woman has a place in society.

- Stanley Dausabea- For always being there for me in good times and bad times.

- My Environmental and Development Studies Masters fellow mates- For keeping our head above the "water" and keeping us sane all throughout. May the friendship go a long the way.

- VUW Support Services- Student Learning Services, Pasifika community, Te Ropu Awhina, Victoria International Office, School of Geography, Environment and Earth Sciences,

- Soluve Village, Solomon Islands- For allowing me to share their knowledge with the world and for looking after me during my data collection.

- Aunty Sharon, Uncle Tom \& Talia - For being my family away from home. 
This page was intentionally left blank 
TABLE OF CONTENTS

ABBREVIATION

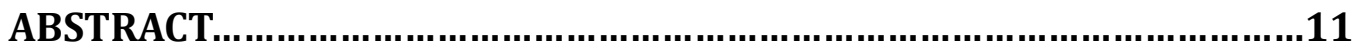

CHAPTER 1: INTRODUCTION.........................................................13

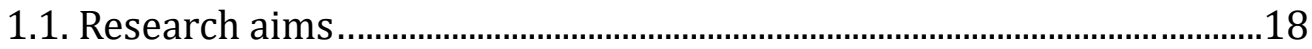

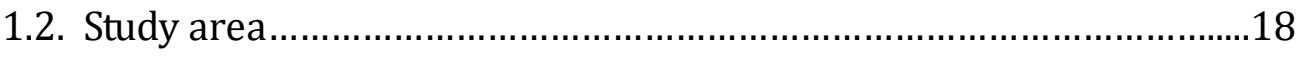

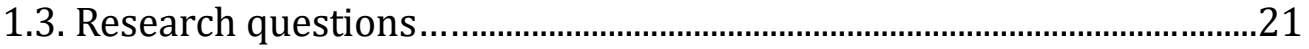

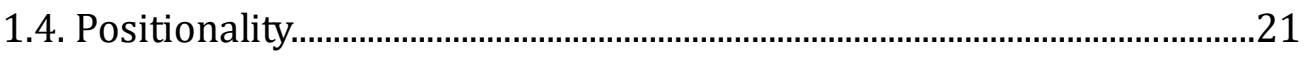

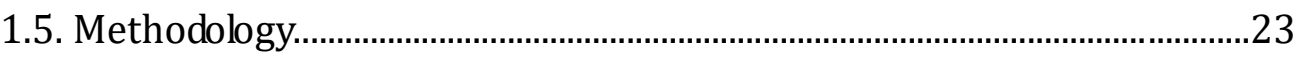

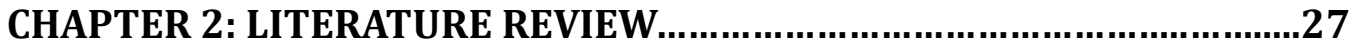

CHAPTER 3: FINDINGS..............................................................................40

3.1. Existing Vulnerabilities and climate change impacts...............................40

3.2. Resiliency in terms of emergency foods....................................................4

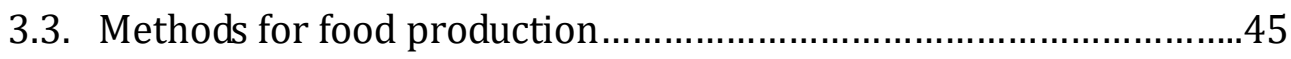

3.4. Growing sustainability of TEK food production......................................4

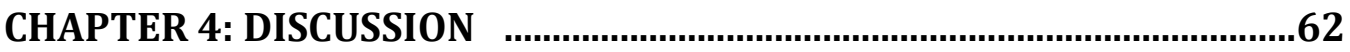

4.1. TEK and Resilient food production.............................................................64

4.2. TEK and sustainability...............................................................................67

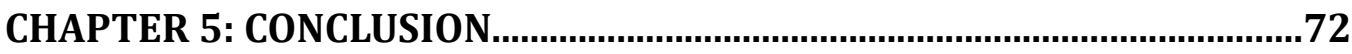

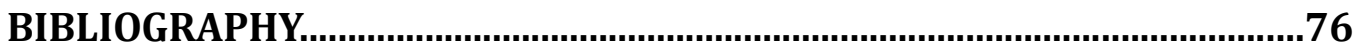

APPENDIX 1: Interview questions.................................................................86

APPENDIX 2: Ethics approval.........................................................................87 
This page was intentionally left blank 


\section{ABBREVIATIONS}

TEK

ADRA

IPCC

IK

IEK
Traditional Ecological Knowledge

The Adventist Development and Relief Agency

Intergovernmental Panel on Climate Change

Indigenous Knowledge

Indigenous Ecological Knowledge 
This page was intentionally left blank 


\begin{abstract}
The study of indigenous peoples and Traditional Ecological Knowledge (TEK) has been of particular interest in recent years. While TEK has been used in areas such as anthropology and conservation biology in the past, little has been done around TEK and resilient food production. The coming years will see the increasing effects of climate change on food production and food security. This research aims to understand and document TEK within the Soluve community in order to understand how people in the community can find ways to be more resilient in the future. In carrying out this research, ten members of the Soluve community were interviewed on food production practices in the light of their knowledge of TEK along with their knowledge of TEK. A thorough search of relevant literature was also central to my research method. The community of Soluve are affected by frequent flooding and rainfall resulting in limited food yields from gardens. The results of my research indicate that TEK is still practised and maintained in the Soluve community in terms of food production. In particular, traditional preservation methods such as smoking and drying in the Motu can help food last longer. Further research is needed, however, on the erosion of TEK, and how the people of Soluve can document this knowledge.

Keywords: [Traditional Ecological Knowledge, Food production, Climate change\}
\end{abstract}


This page was intentionally left blank 


\section{CHAPTER ONE: INTRODUCTION}

\section{'Lulamu ko nyanyio kale nyo me zaiva' (We live on the knowledge of our ancestors)}

Traditional Ecological Knowledge (TEK) has played an important role in assisting indigenous people become more resilient in their changing environments. Traditional knowledge exists among many indigenous communities around the world. Indigenous peoples are located in many parts of the world from the Amazon to Canada. As the world has changed environmentally, many of these indigenous people have adapted to their changing environments. The Pacific Island countries consist of many indigenous groups of people rich in traditional knowledge. TEK is a holistic body of knowledge encompassing a group's beliefs, practices, and way of life. The knowledge and the practices of TEK have been predominantly used in areas such as resource management and conservation but not so much on climate change resilience. The use of TEK within the spectrum of climate change is an important but also growing subject.

Global impacts of climate change include sea-level rise, rising temperatures and increasing storms. Previous assessments by the Intergovernmental Panel on Climate Change have projected that more sea-level rise will occur in the coming centuries (Church et al, 2013). This is expected due to the warming of oceans and melting of ice sheets. Developing countries - including those in the Pacific with small communities are more likely to be affected by the impacts of climate change. Sea level rise and saltwater intrusion are most common in small atoll island nations. Storm surges and high tides pose a threat to coastal communities. These communities are vulnerable to changes arising from factors such as geographical isolation, geographical location and low economic income (Nunn, 2004). Changing environmental conditions have affected both human livelihoods and communities' physical surroundings. As is the focus of this thesis, food production and food security are impacted by increasing storms and sea level rise due to the inundation of gardens and rising temperatures. This is particularly problematic for Pacific Island countries due to their reliance on food production for survival. 
Over the years, many of these communities have developed both an understanding of changes in climate and ways to manage some of the risks that climate change and sealevel rise bring. People have learnt to change aspects of their environment and their behaviours to reduce the impacts of climatic risks.

Much of the research undertaken on climate change in vulnerable areas such as the Pacific uses Western science as a tool for climate adaptation to respond to changing conditions. In certain communities around the world and within the oceanic region, indigenous peoples use another approach to assist in food production. TEK has played an important role in assisting people for many generations in becoming resilient in their changing environments.

\section{Traditional Ecological Knowledge}

The term 'Traditional Ecological Knowledge' has varying definitions. Some refer to it as Local Ecological Knowledge (LEK), Indigenous Ecological Knowledge (IEK) or Indigenous Knowledge (IK). Such ambiguity means there is no universal definition of TEK (Inglis, 1993). TEK comprises a people's way of life, and their understanding of that way of life, including their beliefs about local ecology that have been passed down for many generations, Berkes and Francis, 1999) Whyte, in 2013, states that the different meanings of TEK do not matter; its most important role is to help different people and societies, respect one another. "While there are no acceptable meanings pertaining to TEK, it is only acceptable if it plays an important role by bringing different people and different institutions to a mutual respect for each other's knowledge". (Whyte, 2013)

Different authors argue over the use of the word 'Traditional' because they assume that connotes 'savage' and 'static'. Therefore, the use of 'Traditional' has always been problematic. (Berkes, Colding \& Folke, 2000). Similarly, an earlier paper by Berkes (1993) stated that many find the word 'Traditional' to be inappropriate when referring to indigenous societies such as those of the Native Americans because they have changed over the years. While this use of the definition has been debatable, the use of TEK has been established and used more frequently through the work of the 
International Union for Conservation of Nature (ICUN). Berkes (2000) gives a very simple but straightforward definition of TEK. "TEK is the cumulative body of knowledge, practice and belief, evolving by adaptive processes and handed down in generations by cultural transmission, about relationships of living beings (including humans) with one another and with their environment”. (Berkes, Colding \& Folke, 2000).

We adopt Berkes along with Olsson and Folke's definition of TEK. "People's cumulative body of non-scientific knowledge, beliefs and practices about local ecosystems and their management that evolves through social learning and adaptive processes and which is supported by customary institutions and handed down through generations by cultural transmission" Olsson and Folke (2013)

These definitions were chosen because of their relevance to the study. This research looks at the knowledge of a particular group of people evolving and adapting to certain processes. It also touches on the way this knowledge is passed down through generations. The transmission of TEK is common in indigenous communities. These definitions describes TEK as part of a community's body of knowledge, different practices and what they see as beliefs. These definitions also recognize the ability for TEK to evolve over time: significantly, TEK is handed down from generation to generation. One important aspect of this definition is that it refers to relationships of a human being to another and also a human being to their environment.

\section{Importance of TEK in Solomon Islands}

TEK plays an important role in communities around the Solomon Islands. For people in the Solomon Islands, both livelihoods and survival depends mostly on TEK. TEK dictates the way people build houses, fishing methods, and the way they prepare food. TEK is also used when there are important ceremonies such as marriages, births, deaths or meetings. TEK is vital in the sense that it consists of these people's beliefs, practices and traditions. This is important because it is the people's way of life and guides how they interact with each other and the environment. TEK practices are the norm of society's way of doing things and are vital in passing down knowledge to the next generation. As previously noted, TEK is the way of life, understanding of it, and the beliefs about local ecology that have been passed down for many generations (Berkes \& 
\& Francis, 1999) Like other Melanesian countries, the Solomon Islands are rich in biodiversity and are still intact with their traditional culture. Indigenous people have used their traditional skills, practices, and social systems to adapt to changes as well as manage resources (Pollard et al, 2015). This is quite common in communities in the Solomon Islands. I have decided to carry out this research because I have an interest in the traditional knowledge in my village. This research is unique in that little is known about traditional knowledge in the Solomon Islands. This knowledge is not documented and much of it is slowly degrading.

\section{Is TEK erosion a concern?}

The rate of TEK loss in different societies is of great concern to TEK holders around the globe and in the Pacific. Johnson (1998), argues that the loss of TEK is evident in many communities around the world and the need to document such knowledge is important. Different drivers influence the erosion of TEK within communities. Generally, the loss of TEK is due to industrialization and globalization (Turner and Turner 2008, GomezBaggethun 2009). Industrialization is seen as the main driver for change in societies. Other complex and multifaceted reasons for the erosion of TEK include the influence of formal schooling and the loss of local languages (MacCarter and Gavin, 2011); new religious beliefs such as Christianity which might be dominant in certain areas marketand profit-oriented farming and changes in how land is being used because of development. The influence of Western-based formal education is a major cause of TEK loss. While more people in the villages are becoming educated, they have little or no knowledge of their traditions and culture. Intermarriages are also a cause for TEK loss: when different people from different tribes or countries are married into a certain group of people, newer ways of doing things are introduced. The influence of Westernization has caused some change in indigenous tribes through Western knowledge and practices.

While there is a concern that TEK is eroding in indigenous societies, some experts assert that TEK is evolving, arguing that TEK is adapting to its changing surroundings. The loss of TEK is debatable amongst different researchers. Berkes \& Folkes, (1998) state that although traditional ecological knowledge is threatened, it is always being 
created. Over the years, the literature has taught us that TEK is always changing and never static. TEK is quite often changing due to global changes and pressures, therefore it becomes a dynamic set of knowledge (Gomez-Baggethun et al. 2013 as cited in Barthel, S., C.L. Crumley, and U. Svedin. 2013). In a recent study, Harrington (2015) also argued that the use of TEK is nothing new and continues to evolve. He states that local biological knowledge collected and sampled through the $19^{\text {th }}$ and $20^{\text {th }}$ century have most likely informed the development of modern biology. Olsson and Folke (2001) describe TEK as an integration of placed-based knowledge that contains an evolving body of knowledge, practices and beliefs, held by certain communities, and concerning

their relationships with their surrounding environment in which they are imbedded (cf. Gadgil et al. 1993, cf. Berkes et al. 2000, cf. Gomez- Baggethun 2012 as cited in Barthel, S., C.L. Crumley, and U. Svedin. 2013).

\section{Relationship between TEK \& Climate Change}

The impacts of climate change, alongside the growing population, are likely to be a problem in the future and the local knowledge of people in the Islands may help them become resilient to these impacts. There is also growing literature relating to TEK and climate change. In a recent study, Vinyeta, Whyte \& Lynn (2016) showed that while TEK is not the main factor researchers consider with regards to climate change, a number of Non-profit Organizations and other groups are now exploring the role of TEK in addressing climate change. There is little knowledge of TEK in the Western Solomon Islands, and much less on Vella La Vella. There are still many gaps in these areas, and further research is much needed.

While there is a lot of literature on the use of resilient strategies to cope with climate change, this research will focus particularly on resilient food production by using local knowledge in communities. Food production, for the purposes of this research, will refer to both the cultivation of land as well food preservation. The importance of using TEK in food production is important in different cultures throughout the country. While resilient food production is practiced around the Solomon Islands, there is a limited amount of literature exploring this. 
This research hopes to contribute in several ways. This paper will fill some of the gaps in this area, and hopefully contribute to resiliency strategies and the preservation of TEK in the Solomon Islands. Very little research has been carried out on climate change and food production in the Solomon Islands. There are also fewer examples in the literature linking TEK to climate resiliency in the Solomon Islands. This paper will contribute to the literature around TEK and climate resiliency in the Solomon Islands, especially on Vella La Vella Island. Another significant outcome of this research is that it will help the Soluve community document their traditional knowledge, and thus provide a way for older folks to teach the younger generation resiliency in their communities. This can be a way to promote resiliency within the community for future events.

\subsection{Research Aims}

The aims of this research are to:

> Understand how TEK has assisted with resilient food production and preservation in the Soluve community.

$>$ Understand the impact of Industrialization and Globalization on the growing sustainability of TEK.

\subsection{Study Area}

\section{Solomon Islands}

The Solomon Islands is one of many Pacific Island countries. The Solomon Islands is one of the island nations in the Western Pacific. This group of islands are part of a double chain archipelago, located in the South West Pacific Basin. The country is made up of nine provinces, namely Guadalcanal, Malaita, Renbel, Makira, Isabel, Western, Choiseul, Central, and Temotu. The country comprises volcanic and atoll islands. Figure 1 shows the map of Solomon Islands, a group of more than 300 islands stretched out in the Melanesian region. The country's climate is mostly hot and humid with the rainy seasons from November to April. The dry seasons are between May and October. These seasonal changes are the result of the country's proximity to the equator. The Solomon Islands are rich in terrestrial and marine resources which are very important for local 
populations' livelihood and wellbeing. These resources are, however, threatened by the growing population. The Solomon Islands has a high population growth rate which presents problems surrounding sanitation, health and education (Live and Learn, 2015). The entire population of the Solomon Islands consists mainly Melanesia. There are lesser percentages of other ethnic groups such as Polynesians and Micronesians.

The Solomon Islands are located in the tropics giving the country cyclonic seasons, frequent between March and December. With the cyclonic seasons happening every year, heavy rainfalls and flooding are also common in the region (Rasmussen, et al, 2013). According to Rasmussen et al (2013), the Solomon Islands experiences, on average, 1.4 tropical cyclones within a year. Cyclones some of which count as natural disasters feature amongst other dramatic natural events common in the Solomon Islands. The area is vulnerable to other natural disasters such as earthquakes, tsunamis, droughts and volcanic eruptions. Key hazards of the Solomon Islands include tropical cyclones, earthquakes, tsunamis, landslides, volcanic eruptions, floods and droughts. Out of all the disasters, cyclones and flooding are the most frequent. Because of their vulnerability to these disasters, indigenous people have tried to be resilient by using their local knowledge, beliefs and practices.

\section{Vella La Vella Island}

The Island of Vella La Vella is one of the main islands in the Western Solomon Islands. Vella La Vella consists of high volcanic islands along with dense rainforests. Figure 1 also shows a map of the Western Solomon Islands where the Island of Vella La Vella is located. Tropical rainforests cover most of the inland areas, which consist of popular trees such as the Canarium indicum, as well as breadfruit, sago palms and coconuts (McKinnon, 1972). Shifting cultivation is one of the main uses of land on Vella La Vella. Shifting cultivation is a method that involves an area of land which is cleared, burned and cultivated into a garden. After the crops are harvested, the area is left to fallow over a long period. This allows farmers to move to other areas to work on other lands for new gardens (Live \& Learn, 2011).

McKiddon's early work on farming and economic development on Vella La Vella illustrated how traditional farming began with stones and lighter debris left to 
decompose. The flora and fauna of Vella La Vella is similar to that of the rest of the Western Solomon's. Bats and possums are common inhabitants of the forests while settlers introduced dogs, mice and pigs (Mckinnon, 1972). The main languages of Vella La Vella are quite different from those of New Georgia, especially the Mbilua Dialect which is non-Austronesian like the other 18 different indigenous languages in the Western Solomon Islands (Woodley, 2002).

\section{Soluve Community}

North of Vella La Vella Island is the small community of Soluve (shown in figure 2). The Soluve community is a community resettlement from the neighbouring island, Vese. The community of Soluve previously lived on Vese Island until an 8.1 magnitude earthquake struck the Western Solomon Islands and caused a tsunami in 2007. The event caused the subduction of two plates, leaving parts of Vella La Vella under water (Swarze et al, 2011). The community of Soluve moved from their original village to the mainland to live on higher ground; the island of Vese was, at that time, no longer habitable. The new community which formed on the mainland was named Soluve, a combination of the names Vese, the island and Soluasi, the mainland. The name signifies the community's new beginning, but also remembers the one they had before (Gomese, personal communication, 2007).

The community has about 30 permanent residents. Other members of the community have moved away or married to another island or village. Others have moved to the capital Honiara for education and employment purposes. Because of its geographical location, the Soluve community is isolated from the rest of the Island. While a number of people from the village have moved away to other villages as well to urban areas, many of them remained in the vicinity of the community. The community had depended on the forest and surrounding ocean for survival long before the influence of Western traders and Christian missionaries. The community is located where there is little development and environmental degradation. While development through logging has impacted their neighbouring villages, the people of Soluve have the benefit of a healthy reef and virgin forests. 

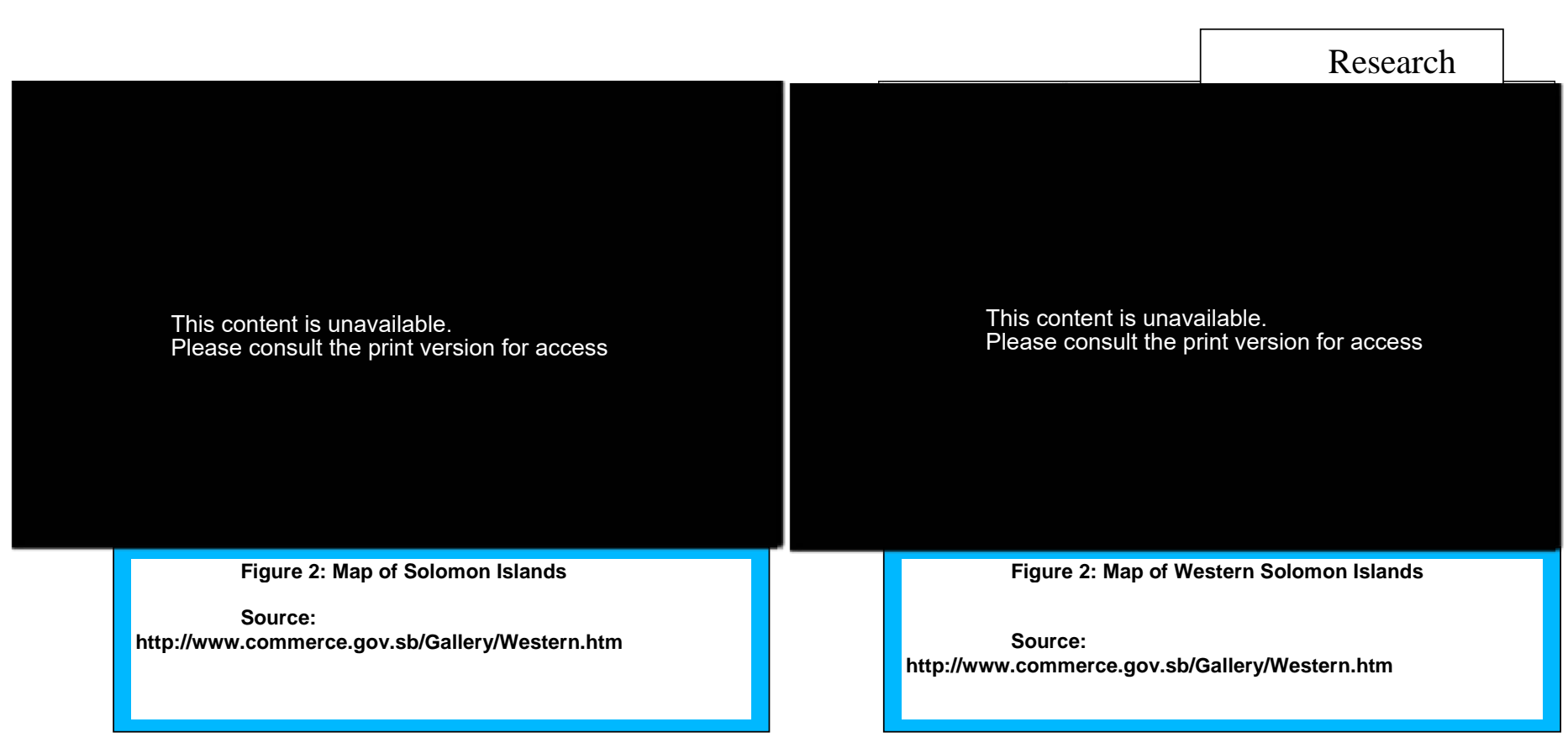

\subsection{Research Questions}

The two main questions of this study will be:

1. How is TEK used in the Soluve community with respect to resilient food production?

2. How sustainable is TEK within the Soluve community?

\subsection{Positionality}

This research area is of personal interest to me as a Solomon Islander. I was brought up in a well-educated family and we lived in the main town for most of my time growing up. I was spoken to in the Solomon Islands pidgin which was the Lingua Franca. Since I grew up outside the village I knew very little about most of the traditional knowledge which was passed down from my grandfather and grandmother to my other cousins. I was also my grandparents' first granddaughter to complete high school and go on to university. I had a lot of Western knowledge to share with the villagers, but I also missed out on the traditional beliefs and practices of the tribe. For this reason, I gained an interest in Traditional Knowledge, but also as an environmentalist, I was often fascinated with the traditional ways in which the old people used to survive during a 
disaster. I have also seen the growing importance of climate adaptation in the Western Pacific and the importance of retaining TEK in small island communities.

Worldview, experience and approach is important for a researcher when his or her research is being carried out. As a researcher I am aware of my position in relation to the topic of my research. It is important to recognize the different power relationships between the researcher and the interview participants. I am also aware of my relationship to the Soluve community as I am from that community. Having a similar background to the participants can have a positive contribution to the research as I am able to understand the background and my relationship enables me to be accepted in the community. I am also aware of my position as an educated university student and that this factor can have an impact on how the informants answer my research questions. During my interviews I've learned that participants were willing and comfortable with me interviewing them because I was an insider and from the same area. I have been to Soluve for the past 20 years and I have become one of them. This has enabled the participants to freely speak. On the other hand, I have learnt too that as an academic I represent the university, and am also seen as an outsider to some extent. For instance, I noticed that some participants were open and relaxed before the interview started but when I started to ask questions, they became shy and didn't talk much. To do justice to my research and to the participants of my research, it is critical to be aware of my positionality as a female researcher from Victoria University, but also seeing myself as young woman from Soluve community who is interested in how those in the community are using their knowledge to reproduce and preserve food. 


\subsection{Methodology}

A qualitative Approach

Based on the aims and objectives of the study the methodological approach of this research will be qualitative. This approach comprises "The multiple meanings of individual experiences, meanings socially and historically constructed with intent of developing a theory or pattern" (Creswell, 2003).

Within the qualitative framework, the researcher will try to establish the meaning of experiences and phenomena from the responses of the participants. This research aims to understand the dynamics of a culturally-bonded group and how this group has developed patterns of knowledge over time. A qualitative approach is selected because this research seeks to understand the behaviours and the experiences of people in the selected community. It allows for participants to share their experiences on a particular event and how they felt about it. Since very little research has been carried out on the topic of TEK in the Solomon Islands, a qualitative approach is an advantage. This is because the people of Soluve were able to share their experiences concerning food production and how they have responded to disasters using their local knowledge. A qualitative approach also allows for more details to be factored into the research context. With little information currently available in the Solomon Islands, the qualitative approach allows for more understanding into the topic. This research is quite limited due to time constraints, and so the qualitative methodology facilitates indepth results within the allocated timeframe.

\section{Methods}

Two main methods were used in this research. A semi-structured interview allows for more flexibility in order to gain more in-depth information. Semi-structured interviews will allow for more understanding and depth into the stories of the people of the Soluve community. Respondents may be able to express themselves more when participating in a face-to-face interview. Some interviewees may disclose more during a face-to-face interview than completing a written questionnaire or participating in a focus group (Creswell, 2003). This is beneficial for the people of Soluve as many of them have little formal education. Most of the population in Soluve have not completed primary or high 
school. Interviews will allow members of the community to explain their answers in a more efficient way and without the presence of others. Another reason for using faceto-face individual interviews is because it is more convenient for members of the community given their day-to-day routines. A limitation of this method is the time consumption and the possibility of being biased. (Woods, 2011).

In interviews, in-depth knowledge on each participant may be gained. The interviews were carried out in a particular area chosen by the participant. These areas were mostly in front of the person's house, a meeting place or in their sitting area. This allowed for a more comfortable and relaxed atmosphere for the person being interviewed, and for disruptions to be avoided. Most of the interviews were done away from the rest of the community, mostly in the participant's home. Interviews were audio recorded to allow the flow of the interview without any disruptions. A total of 10 interviews were carried out and these often lasted between 10 minutes and 40 minutes depending on how knowledgeable or interested the participants were. The interview schedule is included in Appendix 1. These interviews were prearranged through letters and phone calls before meeting the respondents. Four of the interviews took place outside of Soluve village, in Honiara, where the participants were temporarily residing.

A review of the literature was also important to the research methodology. . Literature was taken from journal articles, books, scholarly journals and reports. Most of the literature was based on a Pacific Islands setting, especially the Solomon Islands. Literature on TEK in the Solomon Islands was searched as well as on other Pacific nations and other countries.

\section{Participants}

A total of 10 participants were interviewed. Ages of participants ranged from 23 to 63 . Both males and females were interviewed because this research aims also to find out the difference in views between males and females. Males and females play different roles in the community so by interviewing both genders, one can understand the reasons for their responses. Women were interviewed as well as other men in the 
village because they play an important role in food production and preservation. The different age ranges of participants shows how differences in age range effect the knowledge of TEK in Soluve. Different people in the Soluve community will have different experience and knowledge of TEK. Interviewees were recruited through community gatekeepers including the village chief, although such gatekeepers did not directly influence the researcher's choice of participants. Given the research's focus on traditional knowledge, most of those interviewed were middle-aged to elderly - that is, those who tend to have more knowledge on TEK. The interviews, however, also included youths.

\section{Data Analysis}

The qualitative results in the interviews were audio recorded, translated and transcribed. Once all interviews were transcribed, they were analyzed using Nvivo software. Nvivo is qualitative software which enables efficient coding and analysis of data. Analysis was done by highlighting and grouping together the different themes. Although Nvivo helps with analysis it does not analyse the results directly for the researcher, but rather helps organize the data for the researcher to then analyse.

\section{Ethical and safety issues}

Ethics approval was granted before research was carried out in the community. When carrying out research that focuses on people of a particular community, and their experiences and knowledge, one has to be aware of respondents' confidentiality and to respect their privacy. On her research on indigenous peoples, Smith (2006) highlighted that respect is consistently important in indigenous communities and is reciprocal between researchers and the community as they are with their environment. This means that the respect that exists between the researcher and the community is the same with the respect between communities and the indigenous environment. As a researcher, I am aware of the customs of the Soluve community and I am also aware of my conduct in representing the university. As a researcher, health and safety is important to consider. The study site requires sea travel from island to island, therefore it is important to be aware of the safety issues. The community is also far from a 
medical centre, so health issues must also be considered. This research was conducted an act of reciprocity which aimed to give back to the community.

\section{Chapter Summary}

This chapter highlights the significance of TEK research as this study will contribute to such research development in the Solomon Islands. The study will also help local communities learn to produce resilient foods during disasters. The aims and the objectives of this research are stated here as well as the research questions. There is little research being carried out in this field and, in this way, the research is significant. Climate change is a problem in small developing countries and understanding how to cope with its impacts is a significant part of this research. The study site takes us into the Solomon Islands with a brief outline of the climate, culture and geography. Soluve is a small community of less than 50 people who are strongly tied to their traditional customs as well as to the environment. The methodological section explains the qualitative approach taken by this research. There were 10 interview participants, selected through purposeful sampling. After the fieldwork, interviews were transcribed and analysed. Other important parts of the methodology are the ethical approval section and health and safety issues to be considered. My positionality is also very important so I acknowledge that I am aware of my relationship with the participants and how this will affect my research. 


\section{CHAPTER TWO: LITERATURE REVIEW}

\section{Chapter Introduction}

This chapter reviews all the literature around the topic. It will review literature around climate resiliency in the Pacific Islands region as a whole and look at the vulnerability of Pacific Islands communities. It will also review what authors say about the use of TEK in climate resilience. The cultural way of life, alongside TEK, is discussed within the literature as vital for indigenous people in different communities such as the Solomon Islands. The chapter will discuss issues around traditional agricultural practices, and food preservation. It will further review literature surrounding the loss of TEK within indigenous communities and how this is an important issue to address. A theoretical framework is constructed based on the different concepts and ideas with the literature which exists regarding the research topic.

\section{Climate resiliency in Pacific Island Countries}

Climate change is a global issue and one that is affecting certain areas around the world more than others. According to the literature, many indigenous communities, especially those along the coast, are going to be vulnerable to the impacts of climate change. The impacts of climate change are evident in many low-lying countries and among those of the developing countries particularly those in the South Pacific. Many indigenous communities in the Pacific Islands are becoming especially vulnerable to the impacts of climate change. Communities along the coasts are likely to be affected by sea level rise, storm surges and heavy rainfalls (Leonard et al, 2013). Indigenous communities are more vulnerable because of their geographical location and remoteness from the outside world. While these communities are more impacted by the effects of climate change, they are often well-placed to adapt to such changes in their surroundings because of their traditional knowledge. Traditional knowledge can be seen as a library containing the knowledge required to cope with certain changes in complex ecological systems. TEK helps communities connect the present to the past to re-establish resilience. This means that TEK helps one understand the complex 
responses required to improve coastal communities' chance of survival (Berkes, Colding \& Folke, 2000). Food security will be affected tremendously by the current changes in climate and associated sea-level rise.

\section{Role of TEK in climate change resilience}

The role of TEK in climate change resilience has recently become popular in the Pacific Islands. TEK has been relied on in terms of resource management. Aswani and Hamilton (2004) looked at the incorporation of indigenous knowledge and the way land issues are managed. Studies have been carried out to examine the way local fishermen can manage ocean resources in the Roviana Lagoon in Solomon Islands. A similar study in Fiji also examines the place of marine species such as sharks within the Fiji Islands and people's indigenous knowledge of them (Rasalato, Maginnitty \& Brunschweila, 2010). The study showed that traditional knowledge and customary law is an important tool for the sustainable management of natural resources in the Pacific. The fourth assessment report from the United Nations Intergovernmental Panel on Climate Change (IPCC) includes case studies of "indigenous knowledge for adaptation to climate change" from the Artic and South America, but none from the Pacific Region. It wasn't until the Asia Pacific Adaptation Forums between 2010 and 2012 that discussions were drawn to the importance of local knowledge in relation to climate change. According to Leonard et al (2013), very little attention has been directed at TEK and communities' perceptions of how they are responding to changes in the environment. Local communities tend to be more resilient because of their knowledge surrounding their environment.

Small island nations have been somewhat resilient to their harsh environments. During the last decade or so resiliency was first used as a descriptive tool and a leading concept for analysing sustainability (Adger et al. 2005; Folke 2006;). This introduces the viewpoint that TEK is thought to increase the interaction between human and environmental systems in dealing with changing conditions (e.g., Berkes et al. 2000; Folke et al. 2003). 
In saying this, these definitions refer to a resilient system as less vulnerable to shocks across a period of time and more able to recover from such shocks. The role of traditional knowledge in building resilience to disturbance can be especially critical for communities that rely on ecosystem services as primary sources of provisioning or income (Berkes \& Turner 2006). The Pacific Islands are able to cope and respond to extreme events such as cyclones and droughts. For example, the swamp taro is used as an emergency food in times of natural disaster. This is quite useful in atoll-like islands in the Pacific. However, swamp taro is also eaten as an emergency food in bigger Melanesian countries such as Fiji and Solomon Islands. Resiliency can also mean being able to build strong traditional houses using vines and raw materials. Indigenous communities have long practised the art of resiliency. They have learnt to adapt to their changing surroundings. Mallikarjuna (2013) states that "Local people are the on-site land managers who play central roles in adapting agriculture and food systems to meet their needs under changing climate conditions. The concept of adapting to climate impacts is not new to them".

TEK has contributed to communities' resilience because of their knowledge of their surroundings and of natural and hazardous events. TEK proved to be a main contributor to the survival of indigenous communities in Gizo during the 2007 Tsunami. A study on the Solomon Islands 2007 tsunami showed that fewer indigenous people in Gizo died compared to Gilbertese migrants who had no stories passed down to them concerning disasters such as tsunamis. While Bell \& Taylor (2015) agree with this statement, they found that there is a need to improve traditional ways of responding to extreme events and conditions. They highlighted other ways such as the involvement of women and the need to involve locals in decision making.

\section{TEK: A cultural way of life}

The significance of indigenous knowledge, especially in the area of social change and development, has been of increasing interest in recent years. For many centuries, humans have depended on their surroundings for survival. Inglis (1993) highlights the importance of TEK since the time of hunters and gatherers. It was not until the early 1980 's that the term became more popular. TEK does not necessarily mean one body of 
knowledge, but it can mean a way of gathering different knowledge (that is, knowledge from different sources) concerning medicinal plants, ceremonies, food preparation and hunting skills. For many countries in the Western Pacific, traditional knowledge and its practices are a cultural way of life. A study by McCarter \& Gavin (2011) finds that "Customary knowledge and practice (collectively termed kastom in Bislamaii) is described as the 'bedrock' of everyday life in Vanuatu, and there is an inter high level of cultural continuity throughout society".

Cultural knowledge and practices are part of the daily routine of many people living in rural areas where horticulture is important (Regenvanu 2005 as cited in McCarter \& Gavin). The collective knowledge of a community consists of their practices, beliefs, values and relationships with each other and with their surroundings. The local knowledge that indigenous people hold about plants and animals are a major component for life and this is shown in the case of Aboriginal people in British Columbia, Canada (Turner et al, 2000). TEK, being a holistic body of knowledge, indicates that people depended on it for survival and it being cumulative, that it was passed down from generation to generation. While TEK is fundamental to the wellbeing of indigenous peoples it is not always wise. For example, in Papua New Guinea, the knowledge people hold on their local biota has had a tremendous impact on the land (Diamond 1993 as cited in Berkes, Colding \& Folke, 2000). Similar experiences can be seen in the lives of the Roviana people, whose traditional knowledge of seasonal fishing proved to be wrong when compared with scientific knowledge (Aswani \& Hamilton, 2004). Similarly, the people of the Fiji Islands, especially on the main island of Viti Levu, make use of sharks as a source in accordance with traditional myths and legends (Rasalato, Maginnity \& Brunnschweiler, 2010). Similar to fishing, traditional agricultural practices are also integrated within the TEK system for indigenous people and especially for those in the Pacific countries.

\section{Traditional agricultural Practices}

Subsistent production supplemented by gathering and fishing has been the main approach to maintaining livelihoods in many smaller communities in the South West Pacific. Research interests in food systems in the Pacific has begun to intensify over the 
years with ethno botanical researches as the initial focus while researches on shifting cultivation have a significant role in developing systems of food production (Levin, 2015). Within the context of Pacific Island countries, traditional food production is a key aspect of survival. Methods of food preparation are often part of the ethnographic study of local and indigenous peoples. Many of the food production techniques are widely practiced around the Pacific. The region consisting of the Melanesian, Micronesian and Polynesian countries have settled into the Islands at a later stage of the Australasian Expansion and in what we know as the Lapita movement (Levin, 2015). Subsistence production, predominantly agriculture supplemented by fishing, gathering and hunting, has traditionally been the main livelihood strategy for most of the smaller island communities in the South West Pacific. Fisheries and non-timber forest products provide important additions to the local diet (Dalzell et al. 1996; Olsson 1991), but agriculture remains the most important economic activity (Hardaker and Fleming 1994). Traditional agriculture is based on tubers in garden plots, often using shifting cultivation (Christiansen 1975), but on many islands cash crops, notably copra, have become important (Christiansen 1975; Bayliss-Smith).

Many traditional farmers in Melanesian areas follow the traditional style of shifting cultivation. This style of farming is also known as 'slash-and-burn' or 'swidden cultivation' (Bayliss-Smith, Hviding \& Whitmore (2003). In an earlier article, Suliana (1984) defined shifting cultivation as the slashing and burning of vegetation while leaving big trees standing. Weeding is a normal process before crops are planted but is also practised during the growth season of the crops. After harvesting, the area is usually left to fallow for around seven years. Many argue that the increasing population in the Islands has forced farmers to reduce the fallow period down to two or three years which is not sustainable (Live and Learn, 2011). An early study in the bilua area of Vella La Vella Island also looked at shifting cultivation as the main form of land use by people in the area. Stone axes and fire were used to clear out the area. Crops planted included a variety of things such as Taro, yam and bananas (Mckinnon, 1972). This kind of cultivation has been practised for many years. Blanco (2013) considered the practice of shifting cultivation to be amongst the oldest cultivation systems in areas around the 
tropics. Bayliss-Smith et al (2003) also show evidence of such practices in bigger Melanesian Islands such as Papua New Guinea and the Solomon Islands.

\section{Food preservation}

Food preservation has been around for many years. Due to many seasonal differences and changes in harvest periods, many of the Pacific Island countries rely on food preservation to keep food for future use. For example, yams are kept in dry conditions like other staple foods such as taro and breadfruit. Different indigenous societies use food preservation as a way to store food to use at a later date. According to Campbell (2014), the most used form of preservation was through fermentation where food is in wrapped in leaves and covered in pits within the earth. Certain articles have stated that preservation practices in larger islands in the Pacific, such as those of Melanesian countries, are not so common.However, Campbell (2006) suggests that food preservation and storing food have been practised throughout the Pacific and also plays an important role in many parts of Melanesia. Food preservation is vital in areas where crops are exposed to and affected by climatic weather extremes.

A common traditional approach to food preservation in the Solomon Islands may be found on Tikopia Island, where locals use traditional fermentation techniques. Traditional approaches to ensure a steady supply of food in isolated areas such as Tikopia includes producing fast maturing and short cycle crops, suitable for planting after a cyclone. This is similar to other cases around the Pacific and even globally. A study by Gomez-Baggethun, (2012) shows that farmers select crops and animals according to climatic and biological conditions. The agro ecological systems as they are called in Doana in Spain are based on traditional approaches to crops such as olive groves and vineyards adapted to drought (Gonza' lez Arteaga, 1993). GómezBaggethun, Corbera, and Reyes-García (2013) also examined indigenous peoples of the Cochabamba tribe in Bolivia who regard global environmental change as part of their local belief system. Although we can say that traditional food production systems are a way of adapting to changes in the environment, Annette et al (2008) state that, traditionally, subsistence production has always been a livelihood strategy for most of the smaller islands and their communities in the South West Pacific. 
Farmers in Fiji also practice preservation in preparation for cyclonic seasons. According to MacNamara \& Prasad (2014), communities are encouraged by elders to use their local knowledge to prepare for extreme events such as cyclones. Similar to a 'motu', a 'lovo' is an underground oven pit used to preserve food for over a week. In the Qeleni villag, elders explained techniques to preserve bananas. Bananas can be cut and hung in a pit using stems and covered with soil with an opening and a small fire. The fire is blown into the pit, ripening the bananas which are buried again, wrapped in coconut leaves. The bananas are left in the pit for over a month before being dug up ready to eat.

\section{Loss in TEK in Soluve}

As rich as the knowledge of communities of indigenous peoples is, TEK is starting to fade. Since the industrial revolution globalization has expanded from Europe to other parts of the world, bringing changes (Gómez-Baggethun, Corbera, \& Reyes-García, 2013). Scholars attribute the loss of TEK to many factors. These factors involve complex and multifaceted reasons. These influences include: formal schooling and loss of local languages (McCarter and Gavin 2011, Reyes-García 2013); dominant religions (Tang and Tang 2010); changes in land use market integration loss of access to resources through conservation programmes (Gómez-Baggethun et al. 2010); mechanization of resource systems and, more generally, industrialization and globalization (Turner and Turner 2008, Gómez-Baggethun 2009).

Research on TEK in Vanuatu shows that Ni-Vanuatu scholars have raised their concerns regarding the fear of losing TEK within their societies. This has also been found in other parts of Melanesia and in Micronesia. Formal education is the main factor which allows for cultural erosion. Reyes-Garcia et al (2013) examines the way formal schools have influenced the way young people react to the knowledge of older people in the community. Thaman(2008) also describes the disinterest of younger people towards gaining traditional knowledge from elders in the community. The main drivers linked to this loss is the "Spread of formal education, integration into market economies, and the attrition of vernacular languages" (McCarter \& Gavin, 2011). Chhabra, V and Haris, A.A. (2015) examine the various factors contributing to TEK loss in South India. These include modernization, policy interventions and migration. 
Similar cases can be found in a study by Johnson (1992) who argues that this is a major problem and the documentation of such knowledge is important. As in many other countries, environmental knowledge is fading, especially within younger members of communities. A study by Hviding (1999) shows that this has been the case for younger residents of the Marovo lagoon who have spent a long period of time away from the Marovo region and have similarly moved away from subsistence practices. Another study by Fazey et al, (2011), conducted in the Makira province in the Solomon Islands, shows that frequent changes in society are reflected in the loss of kastom ${ }^{1}$ including changes in traditional feasts and practices. Fazey goes on to say that these changes are strongly influenced by a change of attitude within the community.

On a positive note, even as the loss of TEK is debated by many, Berkes \& Folkes (1998) state that while TEK is threatened, it is always being created too. In a recent study, Harrington (2015) also argued that the use of TEK is nothing new and continues to evolve. He states that local biological knowledge which was collected and sampled over the years in the early $19^{\text {th }}$ and $20^{\text {th }}$ centuries have most likely informed the development of modern biology. Olsson and Folke (2001) describe TEK as an integration of placed-based knowledge containing an evolving body of knowledge, practices and beliefs, held by certain communities, and concerning their relationships with their surrounding environment in which they are imbedded (cf. Gadgil et al. 1993, cf. Berkes et al. 2000, cf. Gómez- Baggethun 2012 as cited in Barthel, S., C. L. Crumley, and U. Svedin. 2013). Over the years, the literature has taught us that TEK is always changing and never static. TEK often evolves due to global changes and pressures surrounding the communities, therefore TEK becomes a dynamic set of knowledge (Gómez- Baggethun et al. 2013 as cited in in Barthel, S., C. L. Crumley, and U. Svedin, 2013). J. F. Martin et al (2010) also suggests that new knowledge is always created over time and evolves as changes occur. He states that TEK is evolving and flexible with the unpredictable changing environment. While Pacific Islanders and indigenous groups build their own ideas out of their surrounding oral histories and traditional relationships rather than using Western knowledge, many of their concepts are not developed in isolation but with cultural contact and influence (Rasalato, Maginnitty \&

\footnotetext{
${ }^{1}$ Customs or way of life of a certain community
} 
Brunschweila, 2010). Traditional knowledge is said to be evolving and changing along with the changing world and surroundings.

\section{A theoretical framework}

Thinking back to the research question at hand we look at the different concepts and how they relate to TEK within the Soluve community. TEK plays an important role in the community. Local communities have local knowledge of different plants, animals, trees and food. TEK systems are practised within tribes and especially individual communities. These traditional knowledges have been passed down from generation to generation. Individuals within these local groups are the most respected experts within the tribe on local knowledge. TEK is the knowledge upon which the Soluve community survives. Their day-to-day routine is influenced by links with traditions, beliefs, knowledge and culture. The theoretical framework aims to categorize and describe certain concepts which are important in the study. It also tries to map out the relationship between these concepts and ideas within the research (Creswell, 2003).

In the study of TEK within the Soluve community and its contribution towards resilient food production different concepts can be drawn. TEK is connected to all concepts. TEK involves different systems. TEK influences the beliefs, practices and knowledge that the community of Soluve have. This includes practical systems such as hunting, diving, planting, gathering food or fishing. It is humans' way of survival. Local communities are also aware of the harvesting seasons, habitats and geographical locations of certain populations or the process of producing food. Food production can be viewed as being practical. Food production can involve a lot of processes. TEK sets the scene for food production in Soluve. The values and practices of a community influences food production. Different methods of food production are mentioned in the Soluve community. Food production is known to be one of the oldest traditions of human civilization.

I have constructed a conceptual model to illustrate my framework on the four main ideas. The first is the context for food production which examines the background of 
the climatic issues within the Soluve community. For example, frequent rainfall and flooding is a major problem in the village, causing threats to food security and food production. Other natural disasters include droughts, earthquakes and tsunamis. The second idea pertains to methods for food production which include preservation and food cultivation. Shifting cultivation is a common traditional practice in the Solomon Islands. Crops are cultivated through the clearing of land and burning of areas before the planting of food such as yams, bananas, taros and potatoes. Food preservation involves drying, cooking and fermentation. The main type of food preservation is drying breadfruit nuts and ngali nuts on the hot stone oven, a traditional practice in the Solomon Islands.

The fact that TEK is changing within indigenous societies is a growing concern in Melanesian societies in the Pacific. Different factors have contributed to the increasing loss of certain knowledge in indigenous communities, especially in the Pacific Islands. These factors include formal schooling and the loss of languages (McCarter \& Gavin, 2014). Examples can be seen in the Makira Province in the Solomon Islands where the loss of kastom is strongly influenced by people's attitudes. But whether the knowledge is eroding or evolving, there is a need to document these knowledges.

The final main idea is based on the transmission of TEK in the community. Growing the sustainability of TEK for food production is vital for communities. Berkes' definition of TEK simply states that TEK has been passed down through many generations ("handed down by cultural transmissions" in Burkes' words) through the means of observations and cultural practices.. The knowledge and practice of indigenous people are known to be passed down through songs, stories, art and dances. Knowledge transmission is most often passed down by the elders in the communities or the parents of the children to their children. Women also play an important role in passing down knowledge as they have an important role in the home and in food production, especially in the Melanesian culture. Women have a significant amount of knowledge when it comes to food production in the Solomon Islands (Pollard et al, 2015). 
The theoretical framework illustrated below gives an outline of the main concepts in this study. The model shows all concepts interlinked with one another, with TEK in the centre. The context of food production in Soluve gives an insight into disasters that have been affecting people in Soluve. The context of food production also shows the different food in Soluve which can act as emergency foods. The people of Soluve are resilient to disasters because they understand that they can survive on TEK when there is no immediate relief from outside the village. They depend on adaptive measures which have been around for many years. Resilient food production is a way of responding to disasters in Soluve. People in Soluve are using TEK to prepare food like sago, kakama and bananas to be able to survive food shortages when gardens are destroyed. The Soluve community also uses TEK for different methods of food production, including shifting cultivation and preservation. For example, 'motu', or the traditional stone oven, is a form of food preservation to allow food to last a long time in the rainy seasons. TEK is fundamental to how the Soluve people produce food. Food production is also part of TEK, which is part of Soluve's culture and community. The villagers of Soluve use TEK to assist in food production, through both gardening and fishing.

As communities are exposed to factors such as intermarriages, formal education and the death of older people, traditional knowledge is slowly eroding. TEK is often forgotten and ignored in this process and it affects the methods of food production because TEK changes as well. Food production and food cultivation techniques have changed or evolved throughout the years. Another concept is the growing sustainability of TEK for food production in Soluve. TEK is important for the Soluve community and in order for food production to be sustainable, TEK must continue to be passed down to younger generations. Knowledge transmission is the way to pass down TEK through stories, chants, songs, or just by observation. Elders in the community have a vast knowledge of TEK in Soluve because they have been around longer. They play an important role in passing down knowledge. They have also experienced previous disasters over the years, and have understood the context of food production in Soluve. They also have seen the way TEK has changed over the years. For many, documenting TEK can be a way to preserve its sustainability in Soluve. 


\section{A theoretical Framework showing main concepts in this study}

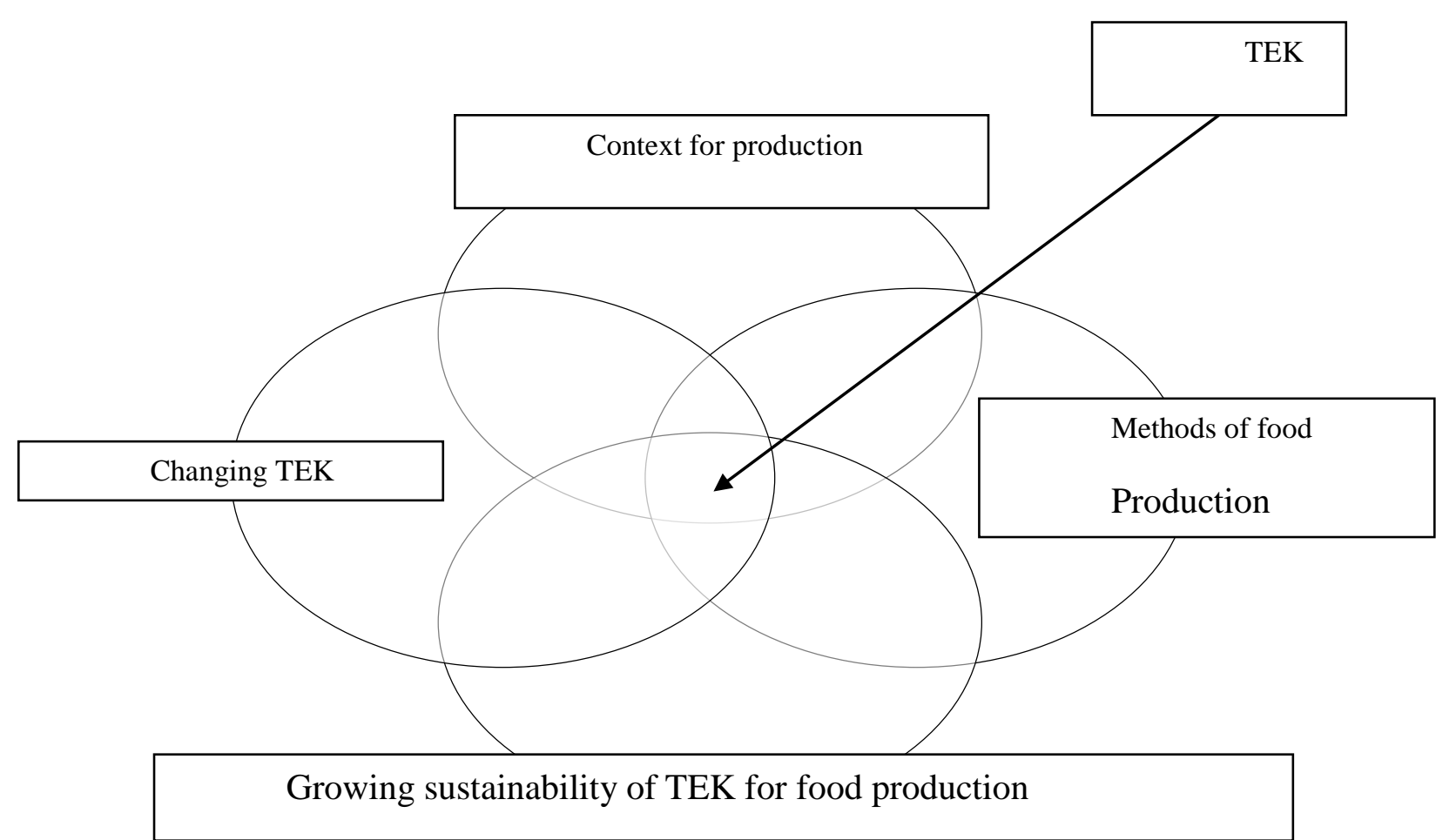




\section{Chapter summary}

The first chapter looks at the literature review surrounding the topic of TEK, food production, and resiliency in the Pacific region and especially in the Solomon Islands. TEK is a holistic knowledge which forms the basis of life in small communities such as the Soluve community. There are different discussions surrounding the definitions of TEK, but we adopt Berkes' version as the knowledge passed down through generations, constantly evolving and influencing humans and the environment around them. While TEK is being eroded in many places, others have argued that TEK is not eroded, but is knowledge that evolves. Traditional food systems are important in communities such as those in the Solomon Islands because their livelihood very much depends on it. Food production through shifting cultivation has been practised for many years, and is a means of survival. Food preservation is a resilient way of approaching disasters in Soluve. The theoretical framework illustrates how TEK influences the context of food production, methods of food production, the growing sustainability of TEK, and how TEK is changing within the Solomon Islands. 


\section{CHAPTER THREE: RESULTS}

\section{Chapter Introduction}

The first theme focuses on traditional agricultural farming systems. All participants focuses on traditional farming methods common in Soluve. The second theme describes the natural disasters which have occurred and are still happening in Soluve. Another dominant theme from the results is the importance of food preservation techniques. Knowledge transmission is another theme. One significant theme which emerged was the role of women in the Soluve community. Other themes include cultural change in Soluve, and participants' responses to retaining TEK within the community. The themes are summarised at the end of the chapter.

\subsection{Existing Vulnerabilities vs Climate Change Impacts}

Changes in the environment have developed over the years. Environmental changes include natural disasters, human-inflicted disasters and naturally changed environments. The community of Soluve has undergone some changes to their environment due to different factors. The Solomon Islands livelihood depends entirely on natural resources. Most of the resources are vulnerable to these disasters and may affect people's livelihoods. The Soluve people, like most Solomon Islanders, have lived through a wide range of human-induced environmental changes as well as natural changes (Hviding, 2012). Many of their resources are threatened by natural disasters. Disasters that were cited by the participants included tsunamis, sea-level rise, heavy rainfall, flooding, wild animals, and land degradation causing poor soil fertility. The main disaster experienced in Soluve by all participants over the years, which was highlighted by the participants themselves, is flooding and heavy rainfalls. This was frequently stated by the participants who were interviewed.

Flooding proved to be the most significant disaster and has been experienced by all participants. Participants stressed how flooding and heavy rainfalls were also a problem in the past. Participants stated that for many years it was heavy rains and destroyed their gardens. Heavy rainfall and flooding from cyclones have destroyed their gardens. As one elder member of the community stated in his interview thatMany years ago, it 
was mostly the heavy rains that spoilt our gardens. Winds were not a problem however; it was mainly the rain and flooding from cyclones or hurricanes" (Participant 4, aged 62).

Participants stated that rainfalls and flooding resulting from cyclones have been the main natural disasters for a very long time. Participant 4 is an older person who has seen the different disasters that Soluve has faced, and has said that rainfalls and flooding have occurred in the past. It was also interesting to also note that Participant 4 relates flooding and rainfalls to the occurrence of cyclones in Soluve. The results also showed the impacts of these disasters in Soluve. Participant 8 describes how they sometimes go hungry when their gardens are destroyed so they don't have enough food to eat.

Most of the participants indicated that gardens were often destroyed by flooding and heavy rainfalls. Food gardens were destroyed because most of their gardens are usually near rivers and streams. If a garden is not located near the river, frequent rainfalls may cause poor production in certain crops such as potato and pawpaw. Most gardens are often destroyed due to its location near large rivers and running water. Gardens that are not not located near a river are often affected by continuous rainfall and this affects crops that are not strong enough such as pawpaw. Other possible natural disasters such as drought, tsunami, sea-level rise and land degradation were thought to have significant impact in the community. While these disasters were mentioned, flooding and rainfalls were the significant disasters to affect the community of Soluve. A lot of the participants who detailed the impacts of flooding and heavy rainfall indicated that this has been happening in the past and has continued over the years. Participant 8 suggested, the people of Soluve sometimes go hungry because the food in the gardens are destroyed.

Given this, sometimes during rainy seasons, certain types of food are put aside to be eaten when there is not enough food to go around. Emergency foods are those foods which are used during times of disasters and can be eaten and preserved for a longer period of time. They are a sort of backup strategy for areas with limited food supplies (Fletcher, 2013). Several of the participants mentioned these types of food and highlighted the importance of emergency food during disasters in Soluve. 
The impacts of climate change are obvious in the Soluve community. While the people have stated that frequent flooding and rainfalls have been part of their changing environments for many years, climate change is certain in these areas and will continue to impact increasingly on the community. It is also interesting to note however, that the people of Soluve state in the research that they have not been affected by impacts evident by climate change. This lack of consciousness of the impacts of climate change may due to the already vulnerable location of the village as a low-lying coastal settlement in which for many years the community has had to develop resilience to disaster. Given the fact that changes to the environment are not immediate, but rather slower patterns of change over time, it may be difficult to differentiate these from their existing vulnerabilities to climate.

However, from the interviews, it is clear that TEK within the community had enabled the community to be more resilient with their surroundings, especially in times of natural disasters. Their knowledge of TEK over the years has developed resilience in terms of production of food and their knowledge of other food sources such as emergency foods. Soluve is rich in its knowledge of TEK, and TEK practice.

\subsection{Resilience in terms of emergency food}

The villagers of Soluve have long depended on certain foods which have served as emergency foods during times of limited food resources. Interviewees highlighted emergency food which sustained them in times of disaster. These included Kakama, Sago and Bananas. For example, one participant stated the importance of the food kakama for the people of Soluve. He stated that they survive on kakama when they don't have food from their gardens and by preserving this food, it may last for several weeks and months. "Kakama is like ADRA for us. The kakama or giant taro we put it in the swamp and we leave it to produce before we harvest them. I think we preserve the foods we eat. I think we just take food and eat it. Oh yeah, because we have swamp food. That is like ADRA for us. So we can survive that. Yes, I think if we motu it and it is properly dried then it will be able to last for two or three days." (Participant 5, aged 57). 
Kakama is seen as a source of relief to the people in Soluve. The great thing about this is that Soluve has several Kakama plantations within walking distance of the communities' houses. Families own their own swamps and often share with other families who don't have their own. In other provinces such as in Malaita and Makira, the traditional preservation of cassava pudding can take up to 3 to 5 weeks' preparation. Apart from being used in cultural feasts, the 6 months cassava pudding preservation is a fermentation process to preserve pudding from swamp taro or cassava. This is used in times of disasters because it can last up to 6 months (Wehi \& Sui as in Live and Learn, 2011). In Soluve, similar processes are carried out in the preservation of cassava although preservation techniques for cassava pudding doesn't actually last for months.

The community of Soluve previously lived on the neighbouring Island of Vese. Kakama do not grow on that island, therefore living on the mainland has given the community access to more varieties of food such as kakama. Participants have referred to kakama as a 'special' food because they only use it during certain times. Kakama is easily planted as well. Swamps are cultivated and the young kakama plant pushed into the ground where it will grow. Sago palm also provide a source of readily available food times of disaster due to the ability to preserve it. Participant talks about the method of preservation of the sago palm. The process of harvesting and preserving sago is briefly explained by participant 7 in his interview which he describes cutting down of sago palm trees and pounding to to retrieve the starch. The starch is then dried out in the sun and this can last for months. "Also, we cut down sago palms which are ready, it falls and we pound it and squeeze its starch out. We dry it in the sun or cook it. When you dry the sago starch, it can last for two months if dried properly" (Participant 7, aged 35).

The sago palm, Cycas revolute, is also an emergency food which is readily available for the people of Soluve. The sago, which is usually used for thatch roofs in the Solomon Islands, is also used for consumption in places like Anuta, Tikopia, Santa Cruz and Kolombangara (Yen, 1974). About 50\% of the participants stated that sago as food is used for emergencies when there is no other food available and when gardens are destroyed. 
The people of Soluve live near the forests,, meaning that the sago trees are easily accessible to the villagers. One tree can feed the whole village. The sago palm tree is popular in other parts of the country and very popular in the neighbouring country of Papua New Guinea. Preparing a sago palm can be hard work so the starch is dried and prepared well ahead of time in case of natural disasters. The results of the interviews indicate that knowledge of preparing sago is known in the Soluve community, especially with the older members.

Another type of food which is found in Soluve and has been a source of emergency food during time of disaster is the banana. Bananas, or vudi ${ }^{2}$, are readily available in Soluve villages because they are located near the houses and are not destroyed by flooding and wild pigs. They are also available throughout the year so they are plentiful in terms of supply. Participants in Soluve can still remember that when other food source has been destroyed, the community has depended on bananas. "I can still remember, one time it was a drought and we only lived on banana and bananas usually grow everywhere in the swamp so we depended on bananas. When our food was destroyed, we depended on bananas. So I can remember when I was little, when there was a flooding or when pigs ate our food, we depended on bananas" (Participant 1, aged 26).

The results indicate that while banana trees are vulnerable to heavy rainfall and flooding, the results indicated that bananas are seen as emergency food during disasters in Soluve because they are planted near the houses and are readily available. The village of Soluve has a lot of banana plantains near every house. These are eaten during shortages of food or during droughts and rainy seasons. Bananas are easily eaten when ripened or are burnt when unripe and eaten. While a lot of food in the gardens are destroyed by flooding or by wild pigs, bananas provide for the people.

\footnotetext{
${ }^{2}$ Banana in the Dovele Language
} 


\subsection{Methods for food production}

Food production is increasingly becoming more important in Soluve. Many farmers in the Solomon Islands still follow the traditional farming method of slash and burn, commonly known as 'shifting cultivation'. Most participants highlighted the practice of subsistence farming in the Soluve community as being important for general food production. For many years, the people of Soluve have cultivated the land through shifting cultivation. As with other Melanesian countries, the Solomon Islands relies mainly on the cultivation of land for their livelihood and survival. Mertz et al (2009) define the process as "a natural or improved fallow phase, which is longer than the cultivation phase of annual crops, sufficiently long to be dominated by woody vegetation, and cleared by means of fire". This process is commonly practiced areas like Soluve and this is how food s planted and harvested.

In accordance with this, the interviews indicated that the process of shifting cultivation begins with site selection before clearing is carried out. This is followed by burning of the bushes to clear the area. Traditionally, the soil is cultivated using sticks to dig up and turn over soil before food is planted. The gardens are weeded by the women during the growth of food, and when the food is being harvested. This 'traditional subsistence agriculture or 'slash and burn' method was highlighted as important practice by the two participants who were the most knowledgeable of this cultivation process. Only two participants mentioned that food production in Soluve is done by the process of 'traditional subsistence agriculture' or 'slash and burn'. In Soluve, the soil is left to fallow after use for two or more years. Figure 3 shows a simple sketch of how shifting cultivation is portrayed in the Melanesian countries. It was also interesting to note that none of the participants mentioned leaving a garden to fallow before using it again perhaps because this has become so engrained in their food production methods so it wasn't understood to be important to talk about or potentially this was due to a small land based which required them to re-use land more frequently meaning they were unable to keep it fallow for the periods suggested above.. 
There seemed to be small variations from community to community. One participant highlighted the fact that farming methods may vary in different communities, and gave the example of the people of Guadalcanal in the Solomon Islands. He stated that, “They cut down the trees and they don't clear the land. They plant the yams amongst the trees. The yams then will crawl up the dead tree trunks. This technique is called Ago or something but I have forgotten it. In some areas, they clear the small shrubs and they plant their crops. Later they cut down the trees onto the crops" (Participant 4, aged 64). Most of the participants also knew about the traditional form of cultivating soil with sticks to plant crops such as yams, taro and potatoes. All the participants stated that they have taken part in food production in the gardens and help out with traditional farming systems. The process which all participants described were traditional farming methods using traditional tools such as sticks

This content is unavailable.

Please consult the print version for access

Figure: 3: Traditional Slash \& Burn (Source: Live \& Learn, 2011)

Food preservation which is also a part of food production, is also practised by the community of Soluve and in other parts of the Solomon Islands. Different preservation techniques are mentioned by participants in their interviews. These techniques include 
motu, the traditional oven to cook food with hot stones, and smoking and drying. Participants mentioned in their interviews that preservation of food was vital both for use during a time of disaster and for prolonging the use of food outside of season more generally. Motu is the main type of traditional food preservation and was mentioned by all participants in the interviews. The process includes placing stones in a circle, the larger ones on the outside. Dried wood and coconut shells are placed inside the circle and a fire is lit. More stones are put onto the fire. When the fire has died down a bit, everything is removed, leaves are placed onto the hot stones and food such as nuts and cassava are placed onto the leaves. The motu is covered up with more leaves and stones. The oven is opened up a few hours later and food removed.

Motu cooking is carried out by wrapping food like potatoes, taro, yams or cassava in banana-leaves along with a few hot stones, and subsequently placing the wrapped bundle on more hot stones. As the food is wrapped in the leaves, the food is both steamed and roasted in the process. Food such as nene (Canarium indicum) are wellroasted by this process, then put in traditional woven baskets known as jari, and placed at the top of kitchen ceilings. The jari ${ }^{3}$ is often used to store food such as nuts for later use. Many parts of the Western Solomon Islands use this to store nuts. People from the neighbouring island of Ranonga use a similar method. The nuts can last for many months, even up to several years.

Participant 10 (Aged 59) stated that "We can dry nuts and place in tins or leaves....tapioca if we want to prepare it as pudding. There is a type of leaf, we call it kalaleko $^{4}$ if we wrap it in it it will last long. Kakama can be preserved through motu and can last two or three weeks. Smoking by fire, in the past cassava and nuts were placed onto one of the jari. These are wrapped properly and place on top of the jari in the kitchen and it will last long". The response from participant 10, one of the older members of the community, indicates the extent of knowledge one has for food production in the community. It was also interesting to note that only this participant

\footnotetext{
${ }^{3}$ Jari is Dovele language for a traditional woven basket to store food like nuts.

${ }^{4}$ Kalekolo is Dovele language for loya cane leaf
} 
talked about the kalaleko leaf which is used to preserve food to last longer. It is only fitting that this person would know more because she is an elderly woman.

\subsection{Growing sustainability of TEK for food production}

Since practices around TEK and food production are said to be eroding and evolving, the desire to retain TEK within the community is important. Soluve's response to retain TEK is to document and keep the cultural transmission alive. All the participants in the interview said that it is important to retain TEK and that this should be done in Soluve for a number of reasons. One of the main reasons to retain TEK was to avoid cultural erosion. Participants felt that TEK must be taught to young people and children so that the knowledge is not lost and that the community is still culturally intact. It was clear from the results that both the young participants and older participants have stated their concern for TEK in Soluve to be retained. It was also clear from the responses of the interviews that they answered confidently and assertively when suggesting that TEK should be retained. Soluve's response is to document and to try and keep the cultural transmission alive. For example, Participant 1 (Aged 26) said, "Yes, I think it is important to keep things from the past so we can preserve our culture from before so it won't be lost. I think it's best if we teach our kids with whatever knowledge we have left which we have learnt in the past. We should teach the next generation so they continue to practise it". Participant 8 (Aged 60) also said, "Teach the children. All the knowledge of our elders in the past is important so teach them (children) so that they will not forget them". Participant 9 (Aged 63) said, "So that it's not lost so we teach our children and they teach their children. We must teach them so they must hear it and keep it in their minds. Yes, because the modern ways are not so good so it's good to use the traditional knowledge".

Most of the elderly participants highlighted the need to teach the younger generations. They have seen the way traditional knowledge has changed over the years. Even younger generations such as Participant 1 stated the need to preserve TEK within the community. The main reason for retaining TEK was because it was important for 
continued community survival and upcoming generations should continue to practise it because it is importantly culturally. Food preservation was essentially understood to be the holder of culture.

This traditional knowledge was also understood by the villagers in contrast to western knowledge. Participant 9, one of the oldest in the community, stated that it is important to retain TEK because Western knowledge is sometimes not applicable in areas such as Soluve and therefore one must know the traditional knowledge. Results indicated that retaining TEK within Soluve is important for the future generations, therefore it is important that younger people know about it and that it is constantly passed down by the older folks.

Another reason for retaining TEK is because the traditional food produced is much healthier than those produced with Western practices. About $50 \%$ of the participants stated that retaining TEK will mean that the knowledge of traditional food production will produce healthy lifestyles which were common in the past. TEK not only provides for a healthy lifestyle but also helps villagers to survive. Participants have been saying that TEK shows them how to produce good food and lessons can be learnt from that. Some participants stated that TEK is important because producing local food is healthier and makes people live a healthy lifestyle. It was stated that in the past people tended to live longer and were healthier. They also stated that introduced food has changed the lifestyle of people in Soluve, bringing in more diseases and shorter lifespans.

Participants relayed their views on the importance of TEK within Soluve. Participant 7 (Aged 35) also commented about traditional knowledge being important for the current generation. The present generation are often seen as the future for the community and having the knowledge of TEK is vital for them. He quoted the words of a few elders whom he looked up to.

"When the elders do something, and it looked new to us and then they explain the traditional way of doing things. They say, 'So that when you grow up you won't lose this because it will be of help to you...We eat the white man's food and we don't live long. Diseases affect us. But before the old people when they use walking stick and they crawl but they are still alive because of how they 
produce food. The local food they use. Oh yeah, because if we lose culture of the old people in the past in how to produce food that shows that we will not live long. It will be because of our carelessness. If we use the old traditional culture in terms of food, we will live long.'

The response from this particular participant indicates the amount of time he has spent with elders in the community. This response also highlights the importance of retaining the traditional foods of Soluve. This also indicates the transmission of knowledge which older people in the communities have and these are being passed onto the younger generations. One important part of the traditional knowledge and traditional foods are that they ensure that people live longer. This has been the experience of the elder people of Soluve in the past where most elderlies live to a very old age. The bottom line here is the survival of people in Soluve. Not only does traditional food production bring healthier lifestyles but it is a form of survival.

Survival is an important part of the community of Soluve. By having the skills and the knowledge around TEK, the younger generations will be able to take on better survival skills and that is why participants felt it was important that TEK is taught to the children in the community. Participant 4 (Aged 62) says,

"Yes, it's good to maintain it because if we accept other ways of doing it, I think the survival of the community. It depends on the traditional method. It's part of the survival of the people. If you do it differently you will start to have problems with how to do it and what to do and where to do it. But if you follow the traditional method or pattern of doing it, the habit to do it, it enables survival in a community especially in Soluve. I think educate the children, the new generations. Our traditional knowledge is still important in our communities like Soluve will survive, will produce same type, same amount and same kind of food that villages produce many years ago. I think if they follow the same method, they will produce the same quality of food production".

Similarly, one participant of 62 years, who had a wider knowledge of TEK in Solomon Islands and its implications. Survival was the main argument for participant 4 because of the changing environment in Soluve; TEK will provide a way for the Soluve community to adapt to its surroundings. This participant also believed that passing on 
knowledge to the younger generation is vital in Soluve. Traditional knowledge is still seen as important in small communities such as Soluve, therefore, teaching the younger generation to carry on the knowledge is important.

TEK transmission is important in Soluve. As the knowledge of TEK is declining, the need for the knowledge to continue with mankind is a must. Knowledge transmission is a way of passing down important knowledge to another person. All interview participants described how TEK was passed down to them. The majority of the participants have learned from their elders, especially from parents, and this should be passed down as an everyday teaching. For instance, participant 1 (Aged 26) said,

"Through observations the knowledge is passed. Usually the mothers pass the knowledge down to their daughters. Sometimes when there are no daughters then the son who is usually at home with the mothers learns from her. Yes, every time, I'm always with my mother and father and follow them. I'm a person who is always interested and always help my mother so everything she has done before when I was little, I can still remember."

It is important to note from this participant's response that time spent with parents, especially the mother, is very important because knowledge is passed down this way. It is also important that sons learn as much from their mothers, even though there are daughters. Many of the Polynesian countries have sons who learn a lot from their parents when there are no girls in the family. Participants in Soluve highlighted the importance of witnessing what their parents have taught them at a very young age. Participant 2 (Aged 23) also stated the same thing:

"So when we're little we live with our parents so the things they practise I grew up with it. I followed what my grandparents did as well as my mother. Sometimes TEK is passed to the first born. Ever since I was small I followed my mother to the gardens and helped out when she cooked food. So I observed what my mother usually does."

One important way of passing down knowledge is through observations. Children are expected to learn from their parents while watching how their fathers and mothers cook or plant food. Grandparents also hold the important role of passing down the 
knowledge. In a lot of families in the Solomon Islands, children are mostly raised by their grandparents. Grandparents have the role of telling their grandchildren stories of the past. Another example comes from Participant 4 (Aged 62), who said,

"For example, the sons, if it is a child who is willing to learn, he will follow his dad into the bush somewhere or out to fishing somewhere and actually watching his dad, copies, imitates him. The mothers show their daughter in different areas such as basket weaving through watching, coping and imitating. That is basically how they do it. Not so much on drawing. They do some artwork, but kids nowadays don't care so much about artwork. Mostly it's an oral learning from mother to daughter or from a father to a son. Imitation has always happened. "To do as I do I already mentioned it. It is passed from the mother to daughter or from a father to a son. Oh grandmother and grandfather come in as well. I looked and copied and watched".

Participant 4, one of the older people from Soluve, also described well how TEK is passed on from the parents and their grandparents. Examples were given around the type of TEK passed on to them. Different practices such as basket weaving and fishing are mentioned here. Artwork was seen as a lost art in Soluve. This was an interesting statement highlighted by the participant. Oral learning and imitation are the main ways that young children learn from their parents. Children are expected to help parents and to learn from them. As an older member of the community, participant 4 therefore has more knowledge but, as an educated person too, responded well to these questions. The observations made by this participant showed his understanding of knowledge transmission in communities. Another older interviewee, Participant 5 (Aged 57), says,“Oh yes, I think by observing. Observing and learning. Before when I was little, they didn't teach me how to cook. I just look and learn. From parents to children. And from the children to their children. Oh, I know that because I followed my parents. For example, when they go to the garden". 
Another participant also stated the experiences he had from his parents and grandparents. Participant 7 (Aged 35) also stated that,

"He has passed it from generations to generations and from parents to their children. I heard it from the old people, and I observed and followed what they were doing. That's how I knew. If it was my own I wouldn't know, but I observed the elders and stayed with them so I know".

Parents play an important role in passing down the local knowledge in a home. It was interesting to hear Participant 5, an elder in the community, say that her parents did not teach her the skills in how to cook food but she looked and learned as she grew up. Most children in Solomon Islands are expected to do that. Although parents do not verbally teach them a certain skill, they are expected to know this skill. The response from participant 7 indicated that the older people in the community played an important role in passing down TEK to younger members. Time spent with older people in the community is seen as very important and is shown as respect to the chief and the tribal leaders. Participant 7 was also someone who had spent all his life in Soluve since birth. Participant 7 is a vital member of the community, skilled with building traditional houses and preserving fish on hot stones. This may be the result of spending a lot of time with older people in the community. As someone who lost a fatherly figure when just a boy, he has depended on the knowledge passed down from his grandparents, granduncles and grandaunts.

Traditionally, TEK is passed down to people in Soluve through teaching and observing. Most of the participants said that they observed their mothers, fathers, grandparents or elders in the community. In Soluve sons follow their fathers to hunt fish and build houses. The daughters are usually with the mothers cooking and going to the garden. The majority of the participants indicated that TEK was passed down to them from their parents and grandparents. Traditional ways are being passed from generation to generation. In most indigenous communities, these knowledges are passed down through stories, chants, songs and dances. They are passed down through generations to generations (Berkes, 1999). For example, this woman is teaching her children how to cook using the motu. 
Women play an important role in Solomon Island societies. This is shown in the community of Soluve. Participants highlighted that the main producers of food in Soluve were women. Men tend to do the clearing, site selection for the gardens, and help women carry out heavy loads after harvestings, but it is the women who do most of the work. The women do not only play a major role in gardening, but in other domestic work such as cooking, Women are said to be the 'backbone of the home'. The role of women in food production has been dominant in the interviews with all participants highlighting the importance of women in Soluve. For instance, Participant 1 (Aged 26) said,

"As I look at my life, it was my mother who always worked in the garden. She usually had three or four gardens when she was still alive. The main producers are the women. All the work, they work and cultivate the soil. The men just clear off the bush in the area and they leave it. Everything is done by the women".

The results indicated that younger participants learnt a lot from their mothers because they spent most of their time with them. The role of women in Soluve can be burdensome because of the work they do every day. One of the participants highlighted how women played an important role in subsistence farming. Each member of the family plays an important role in food production, but the woman does most of the work. Mothers are the main transmitter of TEK within the family and the ones who pass on this knowledge on a daily basis to their children. Participant 4 (Aged 62) said that,

"The father does the job of clearing the bushes but then helps the woman with clearing and burning. Planting is done by the mother but sometimes the man helps out. Weeding is usually done by the mother, and this includes weeding and maintains the garden. The woman plays an important role in harvesting and unfortunately, woman is 'beasts of the burden.' When men are away, women are the only ones that go to the gardens".

Gardening and food production is an important role for women in the community. Men often assist but it is the women who are the sole providers in the family when it comes to food production. When the men are away, women play both the roles of the mother and the father. Participant 4 also stated an interesting fact about women being the 
'beasts of the burden', referring to the amount of hard work Melanesian women are often involved in. A lot of the gardening can be hard work with gardens often kilometres away from the main village. Gardens are often up in the mountains and are not easily accessible to many. Participant 6 (Aged 31) also stated that, "In Soluve, it's the women who work. There are no men so it's the women who do the work".

The women of Soluve play an important role as stated above. Their roles are very important while men are away. Pollard et al (2015), in their research on traditional knowledge in the Solomon Islands, also found that females spend more time in food gardens and at home. Culturally, women do the cooking and food preparation while men are away at war or fishing. Women are often seen as the main provider of their families. The women also play an important role in passing on TEK to their children because of their influence in the home. Participants indicated in their interviews that parents play an important role in passing down knowledge and more specifically women. The results indicate that the role of women is vital in Soluve, especially in terms of food production. They are the ones who prepare and produce food in the village, but also in their homes.

Drivers of cultural change

Cultural loss seemed to be a significant concern for the Soluve community. Interview participants shared their concerns over how cultural practices in the community are eroding. Key reasons they have cited for cultural loss include Western influence, formal education, intermarriages and the death of holders of traditional knowledge. Thaman (2002, 2008a, b, 2013 as cited in Pollard et al) stressed the parallel of an extinction event relating the loss of TEK and biodiversity. In the case of the Soluve community, participants indicated that one of the main reasons leading to cultural loss in the community is the Western influence. This is described as "Save blo oketa white man" or 'the knowledge of white man' (Gomese, 2016). The changes leading to cultural loss are brought by globalization, urbanization and development. Western influences have changed how people speak, do things and dress. Industrialization is seen as the main driver for change in traditional societies. Generally, the loss of TEK is due to industrialization and globalization (Turner and Turner 2008, Gómez-Baggethun 2009). Different drivers of cultural change are stated below. 


\section{Formal Education}

One main reason for cultural loss in Soluve is formal education. Ten years ago, only a few people in the community had completed high school, and only one had reached university level. Ten years later, more children are attending formal education institutions. More and more children are going into high schools and about six people from the community have reached university level A lot of the people who reach university had to move away from Soluve in order to get a very good education. Participants indicated that being away from the village for education purposes has contributed to their lack of understanding in TEK. For instance, one of the interviewees, Participant 4 (Aged 62), stated,

“Other things I didn't learn from my father because I'm always away such as the building of houses. You can tie the house with ropes. I only know a little of that because I'm always away. If I had stayed with my father more I would have known, all details. But there are many, many things I have learnt from my dad. Other things are impossible for me to do such as climbing. My father didn't teach me to climb trees because I'm always away from the village. Naturally, it's not of interest to me. It's a knowledge that you have to accept and follow".

It was interesting to see the response from this elderly participant who moved away at a very young age to get a good education and who has therefore spent a lot of time away from his father. This particular participant was one of the first to reach tertiary education and it was interesting to read his opinion about traditional knowledge in Soluve. To him, traditional knowledge is not of interest, but it is something that one must learn. His views are possibly influenced by his level of education, his time away from Soluve, and his parents. It was clear during this interview that the participant had little interest in the traditional ways because he was mostly away for educational purposes. Dependence on formal education has also resulted in less interest in local knowledge. Pollard et al (2015) reports on children having limited understanding of TEK in Malaita, Solomon Islands as a result of school attendance. This shows that this is becoming a problem in other areas in Solomon Islands as well. 


\section{Intermarriages}

Intermarriages between the Soluve community and other islands and tribes are one of the main causes of loss of cultural practices. Many of the people who married into Soluve moved into the community. The results of the interviews suggest that there are other tribes in Vella La Vella who came from other islands to settle in Soluve. Participants indicated that new residents of Soluve may have introduced other, new methods of production. There are other people who may have introduced new methods, especially those slaves from before, or those who married into Vella. While there is no concrete evidence to this claim, it is possible, as Soluve has had many new marriages from other provinces and islands in the Solomons. A lot of the third generation of people in Soluve have married Asian men who have themselves come to the island to work in logging companies. They have introduced new ways of doing things, but many of the practices are still maintained. Intermarriages cannot be avoided because marrying within the Soluve community and within the tribe will be a disgrace and forbidden by custom. Therefore, people from other cultures may influence the community through intermarriage.

\section{Death of holders of TEK (mostly elderly)}

Most of the people in the Soluve community were 40 years old or younger. Most of the population within the community were youth or children. As stated in the previous paragraphs, elders in the community have more knowledge of TEK in Soluve than younger members of the community. However, most of the elders in Soluve have passed away. In the process of the research write-up, an elderly member of the community who has contributed very much to this research also passed away. Although $50 \%$ of the participants were elders, this does not accurately depict the population of elders within the Soluve community. The common factor indicated in the results was the death of elders who possess TEK in Soluve. According to most of the participants, many of the older people have passed on and therefore traditional knowledge is no longer being passed on to younger generations. One of the participants noted that old people have

passed away and many are not living as long as those of past generations. More young 
people are currently residing in Soluve, and there are now fewer elderly living in the community.

\section{TEK as dynamic}

The Soluve community has noticed a change in the loss of culture in their methods of cooking. Newer methods of cooking are now introduced into the community. It was evident from the interviews that most participants suggested a loss in their culture, but it was the older people who described, in-depth, what methods have been lost. Several participants stated that the way people prepare food nowadays is not like in the past. Some cooking methods from the past are no longer practised by people in Soluve. Older participants also highlighted the changes they have seen, from burning food on hot stones to cooking in pots and pans. "Yes, in the past they only motu and burn food, but now they just cook in the pots that's why they become bad quickly. They cook using pots". (Participant 9, aged 63)

While cooking in traditional earth ovens and burning food on hot stones are still practised in Soluve on a daily basis, cooking with pots and pans are also being routinely used, mostly because the process is quicker. Motu is still everywhere in the Solomon Islands, however it is not practised everyday as a form of cooking. In urban areas such as in Honiara, people use motu mostly during the weekends or for special feasts and celebrations. Furthermore, materials to use for motu such as stones, leaves and firewood is difficult to find in urban areas. While leaves and firewood can be sold in the market, they can be very expensive. Participant 8 (60) also strongly stated how women and cooking techniques have changed over the years. He stated that in the past, people cooked food by burning and motu but now everyone uses pots. He gave an example of how banana is cooked: "One example is that in the past food like banana is burnt on fire, and they always scrape out the burnt parts carefully before giving it to their children. But nowadays women don't do it. They don't bother to do it for kids. So children burn their own food and eat it" (Participant 8, aged 60).

This statement is interesting in that the way women prepare food for their children has changed. Scraping banana skins is a common traditional practice of families in the Western Solomon Islands. While mothers are no longer doing this for their children, as 
stated by participant 8 , children are able to learn this traditional method by doing it themselves. Children as young as 2 years of age are able to use a knife to scrape their own food. Modern techniques were also mentioned by the interview participants; techniques such as boiling in pots and pans, adding salt, putting food in ice, and storing food in tight and closed containers. Nowadays, nuts are stored in buckets and containers to preserve them. These were also mentioned by the participants. Birks (2014) also suggests in his paper on socioeconomic stressors in the reef islands in the Solomon Islands that preservation techniques are still in use, but are not practised in many areas anymore. Preservation techniques are mostly used on breadfruit, which is called 'nambo'. Traditionally, people worked together to dry and ferment different types of food but as participant 8 stated, 'many of these practices have been phased out - perhaps because people "start to look more after themselves, instead of looking after each other'

\section{Cultivation changes in crops, and techniques}

Aside from changes in cooking methods, crop cultivation and their techniques have also changed over the years, and this was highlighted by the participants. Some of the interview participants noticed that the way bananas are planted nowadays is different from the way they were planted in the past. Participants stated that the use of modern tools have taken over the traditional way of cultivating the soil. Tools such as hoes, knives, rakes and shovels have taken over the use of traditional sticks to plant food. Another change is the way the crops are being planted. For example, Participant 1 (aged 26), who learned from his mother from a very young age, noticed a difference in the way her mother planted bananas to the way bananas planted now. Bananas were usually planted in the ground at a particular angle, but nowadays the plant is just pushed into the ground at any angle as long as it is in the ground. Changes in crop cultivation and techniques in Soluve are seen as changes in culture. 


\section{TEK erosion or evolution?}

While there is evidence from the interview respondents that a lot of cultural practices have changed and are starting to be lost, the cultural way of life in Soluve is still strong. Participants highlighted the fact that there is no sense of large cultural loss in Soluve in Soluve. Soluve is located in an area where development has not taken over its community. For example, participant 3 (aged 23) stated that, "Food production is still the same as it was before ... the world we live in now is different from life in the past. So some knowledge of the past is starting to be lost, but there are some who still practise it."

Participant 3, who is young, in her 20 's, highlighted the fact that there is not much difference in the cultural life of Soluve community. According to her, food production seems to be the same as in the past. As a young person in the community she herself has not acknowledged the different changes around her in terms of producing food. But she also says that some such knowledge is becoming scarce as current times are different from the past. Some of the knowledge apparently lost is said to be still practised by some in the community, so it is not completely lost. Furthermore, participant 4 (aged 62) also believed that there has not been much change in Soluve. "I think traditional methods of producing food are still maintained. Maybe other introduced food is prepared in a different way, but traditional methods are still practised in villages, and in Soluve."

According to this participant, some changes in Soluve are obvious, but not all traditional knowledge and practices are lost. As someone who has lived a long life and has seen the way Soluve has changed over the years, the traditional methods are still practised. This is related not only to food production practices but to every aspect of TEK in Soluve. Pollard et al (2015) also argue that TEK may generally grow and expand over time, therefore, although younger generations may have less knowledge as they grow older, this does not necessarily mean that the knowledge is lost. It was interestingly to observe that both the young people of Soluve and the older believed that the traditional knowledge of Soluve has not been completely lost. There have been

a few changes, but many of the people in Soluve have been practising traditional food 
production. This indicates that TEK within communities such Soluve is valued and practised by both young and old.

\section{Chapter Conclusion}

The findings chapter highlights the four main themes that were identified throughout the research. Four main themes were produced through the analysis of the results. The first theme relates to the context of food production in Soluve. Climate change impacts will affect food production in small communities such as Soluve. Using TEK can be a way to produce food that can serve communities for future use. Food emergencies also serve as part of reserving food in times of natural disasters. The second theme looks at the methods of food production in Soluve. This includes food cultivation through the traditional method of shifting cultivation. Shifting cultivation is practised in Soluve as it is also practised in most tropical countries. This is the traditional way of food cultivation in the Solomon Islands and other Melanesian countries. All participants indicated traditional slash and burn as their common traditional way of cultivating food. Food preservation is also part of food production. Preservation techniques discussed by participants included the popular traditional use of an earth oven (or motu) which cooks, dries and helps smokes different types of food.

The third theme is the growing sustainability of TEK for food production. The transmission of TEK within Soluve is important because it is the survival of indigenous people. Elders are the holders of knowledge and it is their role to pass down knowledge. TEK is passed down mainly through observations and teaching the younger members of the community. Women also play an important role in passing down this knowledge as they are the main food producers in Soluve. The final theme which emerged from the results is the cultural loss resulting from several factors such as Western influence, formal education, intermarriages from different tribes and islands, and the death of TEK holders, in particular the elders in the community. While many changes are seen in food production, most participants suggest that TEK within Soluve is still intact and only a little has been lost. Others claim that TEK is not lost, but it is changing. 


\section{CHAPTER 4: DISCUSSION}

\section{Chapter Introduction}

This chapter discusses the main results of the research linking it with the literature which was critically analysed in the earlier chapter. The results are discussed according to the two main research questions. The chapter will also look at whether the answers were answered according to the results. It will look at areas where the results showed that the questions were not answered, and those where the questions have been answered, and giving reasons behind this. The discussion chapter also discusses some of the limitations of the research. It will highlight the main areas which need improvement. The chapter will also look at areas of further research. These observations can be used to justify further research along the same topic to both add to the literature and to answer more questions surrounding the research topic.

The study of indigenous peoples around the world and their use of TEK is important in many societies around the world today. The main aim of this research is to understand and document TEK and how it has assisted with resilient food production and preservation in the Solomon Islands. The impacts of climate change are affecting food security in small island communities such as Soluve village. Research focused on this particularly community because of their strong link to traditional culture, and the environment, but also because of their vulnerability to the impacts of climate change. TEK has played an important role in the lives of the indigenous people of Soluve. The Solomon Islands is rich with cultural beliefs and knowledge. TEK plays a role in their beliefs, practices and knowledge. One of the main forms of food security is through food production and this has been affected by the impacts of climate change. This research has hoped to understand how the people of Soluve have practised TEK in terms of preserving food and storing food during natural disasters. Environmental change in Soluve is experienced by members of the community. The key disasters which were prominent in Soluve were flooding and heavy rainfall. All participants stated that heavy rainfall resulting in flooding were the main natural disasters to affect Soluve. 
The climate and weather changes in the Solomon Islands are increasing and more cyclones and flooding have been occurring in recent years. Heavy rainfalls are quite common in tropical areas such as the Solomon Islands and thus the impacts are quite damaging. The typical weather and climatic features experienced by Soluve are the overall weather systems in the Solomon Islands. The Solomon Islands has a tropical climate and the rainfall ranges from $3,000 \mathrm{~mm}$ to $5,000 \mathrm{~mm}$ depending on the altitude. Cyclonic seasons are quite frequent between March and December and heavy rainfalls and flooding are common (Rasmussen, et al, 2013). On average, the Solomon Islands experiences 1.4 tropical cyclones in a year (Rasmussen et al, 2013). Drought was also another significant extreme events mentioned by several participants. Participants perceived three main types of natural disaster to be the result of climate change. These are (1) cyclones and storms, (2) flooding and (3) droughts. These disasters may not be the important signs of climate change effects, and may instead result from one another such as flooding as a result of cyclones (Rasmussen et al 2013). Other disasters which were experienced by the community were tsunami, and earthquakes. It is interesting to note that local people have an accurate knowledge of the intensity of droughts and flooding-related events which affect their crop production (Gomez-Baggethun et al, 2013).

The Solomon Islands Country Assessment report (2015), also reports that the key hazards of the Solomon Islands include tropical cyclones, earthquakes, tsunamis, landslides, volcanic eruptions, floods and droughts. Due to the inland settlements of the Soluve community and the rich mangrove forests which also act as a barrier, sea-level rise is not a problem. Many of the participants said that Soluve is able to survive natural disasters because of the small population and therefore food is not so scarce. Climate change impacts are obvious in the Solomon Islands with many of the communities along coastlines affected. This research shows that TEK is used within the community in relation to food production, for example through shifting cultivation and food preservation. It will also give answers as to whether TEK is sustainable within the Soluve community or not. 


\subsection{How is TEK used in the Soluve community with respect to resilient food production?}

TEK is an important form of knowledge within the community of Soluve. The traditional knowledge is culturally and spiritually part of the society. TEK important for medicinal purposes, resource management and food production. Food production is an important part of the survival of the community. Many countries such as the Solomon Islands are facing the increasing impacts of climate change and food security is an issue is many island countries. TEK is therefore, used to produce food which will be able to cater for people in the community. The production of food will be an issue since the impacts of climate change will be affecting food. Many indigenous communities are using their local knowledge of how to produce food and preserve it in times of food shortage or in a state of emergency.

The main findings of the research indicate that the people of Soluve use resilient food production such as shifting cultivation and food preservation. As shown in the results, the impacts of climate change have long existed within the community, but has been seen as "normal" because of TEK. The Soluve community's understanding of TEK helped them become more and more resilient when it comes to natural disasters. The practices they have maintained over the years, and the knowledge they have carried with them, has made their community resilient in such a way that climate change impacts are not seen as a threat to the community. Using TEK was instrumental in producing resilient food production and food preservation. Food production in Soluve is based mostly on traditional farming: the shifting cultivation method known as 'slash and burn'. Shifting cultivation is widely practised in Melanesia and other Pacific Island countries. Through many years, countries like the Solomon Islands have practised shifting cultivation without depleting most of their resources. Traditionally, sticks are used to dig holes and soil to plant different crops such as taro, yam and potatoes (Siwatibau, 1984). Both younger and older participants mentioned this in their interviews, showing their knowledge of traditional cultivation techniques. A limitation in this area is how shifting cultivation can be related to resilient food production. It can mean either the planting of more resilient crops as part of traditional cultivation techniques or the diversification of crops. 
McKinnon's early work in Bilua on Vella La Vella examined shifting cultivation as a principle form of land use by people. The process was described as the use of stone axes and fire to clear the area. Crops that were usually planted were taro, banana, sugarcane and yam (McKinnon, 1972). Furthermore, the people of Soluve have been practising traditional agriculture for many years. This is supported by Blanco (2013) who considers shifting cultivation to be one of the oldest cultivation systems in tropical regions. Shifting cultivation is considered to be the main cultivation system in the bigger islands of the South Pacific such as Papua New Guinea and the Solomon Islands. In Soluve, shifting cultivation is seen is the main for in which they make gardens to plant food.

Many of the Pacific Island Countries such as the case of the Soluve community whereby shifting cultivation was widely described as the main form of food cultivation activity (Bayliss-Smith et al, 2003). Olsson (1991) also suggests that subsistence agriculture is a traditional form of livelihood for many of the small island communities in the South West Pacific region.

Traditional food processing and preservation includes techniques such as drying and smoking in Soluve. Most importantly, the main traditional way of preparing food in Soluve is by cooking local food in the traditional earthen oven, the motu. This is common in the Pacific and especially in traditional societies. Hagen (2013) reports that Melanesian survivors largely relied on traditional ways of cooking, such as motu cooking and 'bo-ne bo-ne'5 cooking. Preservation techniques are used for staple foods such as taro, breadfruit and banana (Thaman, 2008). The results showed that the younger participants did not know much about preservation techniques. While most of the participants stated that motu was one of the main ways of cooking and drying food like cassava, nuts, yams and bananas, two younger participants did not mention any preservation techniques and were unsure about the questions. A reason for that might be because of limited knowledge around food preservation and its importance in Soluve. It was also interesting to note that participants who were unsure about traditional preservation techniques. The details of other preservation methods, such as the

\footnotetext{
${ }^{5}$ Solomon Pidgin for burning food on hot stones.
} 
smoking of fish and the drying of fish and breadfruit in the sun, were not explained in detail by participants. This might be because these practices are not common.

Emergency foods, also referred to as 'Famine Foods' (Campbell, 2015), are not usually consumed but can be used in emergency situations. Emergency foods can range from those planted to those naturally grown in the rainforest. Emergency foods include nuts, yams and breadfruits. The giant swamp taro (Cyrtosperma merkusii) is an important staple food in the Pacific Islands especially atolls (Englberger et al, 2008). These are also found within swampy areas of larger Melanesian countries like Papua New Guinea and Solomon Islands. Giant taro, commonly known as kakama in the Solomon Islands, are readily available in Soluve in swampy areas not far from community homes. The swamp taro is a mainstay of the people of the Pohnpei atolls, providing food security for those living with the natural remoteness of the atolls (Englberger et al, 20018). It was interesting to note that the kakama plant was referred to by a research participant as an aide to the people of Soluve in times of natural disaster. Kakama was referred to as ADRA, a humanitarian NGO which serves to aid people in times of disaster. This showed the importance of kakama in Soluve as an emergency food in times of food shortage.

TEK is used to plant, harvest and preserve food like kakama. Kakama are planted in swampy areas with traditional sticks which are pushed in to the ground to enable the new planting of young kakama plants. One interesting fact about using TEK with resilient food production in the case of the swamp taro, was that the people of Soluve used TEK values and beliefs of family and sharing. Not all families in Soluve own a swampy garden of kakama, but it is always shared amongst the villagers themselves when a family needs it. This goes to show that TEK in resilient food production goes far beyond cultivating practices, but also reflects the values and beliefs that bind the community together.

Another emergency food is the sago from the sago palm which can be dried and stored for a long period of time. Sago is consumed in other parts of the Solomon Islands such as in Tikopia, Santa Cruz Islands and Kolombangara Island (Yen, 1974). The Soluve community depended on sago because it is readily available and close to the village. One palm tree can feed the whole village. With the small population of the Soluve 
community, a single sago palm can feed the entire village. The pina or sago is used as an emergency food where it is dried in the sun after removal from the palm. The dried starch can be used at a later date. The dried starch is now commonly kept in well-closed containers to keep it dry and avoid any moisture. An interesting emergency food in Soluve are bananas, abundant around the houses in the Soluve community. While bananas are plants which can be destroyed during a cyclone or flooding, it is an emergency food for the people of Soluve because they are located close to their homes and are readily available. There is no evidence that bananas are used as emergency food in other parts of the Solomon Islands, but is the case in Soluve. Bananas in Soluve are planted, harvested, and kept in small kitchen huts to ripen. They are eaten at a later date, but can also be cooked when they are unripe. Emergency foods serve as a best food source available for the people of Soluve when other main food sources are unavailable.

\subsection{How sustainable is TEK within the Soluve community?}

TEK is commonly known to a group of people within a community, but it can also be communal knowledge for that community. TEK is commonly held collectively within a community or society. Some aspects of it are knowledge available to all, and other aspects restricted to a certain age or gender (Leonard et al, 2013). TEK is a collective knowledge, held in informal institutions by the village elders and passed down through many generations. The results indicate that TEK is mostly passed down through observations. Younger people in Soluve know most methods of food production having watched their parents. It was also interesting to note that other methods of knowledge transmission, such as dances, singing, storytelling and chants, were barely mentioned. This is probably because in most cases, knowledge is transmitted by learning without teaching. A child learns from his or her parents because she is expected to know these things once she grows up. Traditional practices such as fishing or gardening are passed down through generations and it is fairly common in Soluve to know how to make a garden and plant common root crops.

The practice of TEK within the Soluve community is still sustained by its residents. The sustainability of their practices and the local knowledge which they procure from their 
parents and grandparents are sustained through the passing of local knowledge through observations. Results showed that young people are able to learn about past practices from their parents or grandparents for many years. This shows the importance of knowledge transmission within an indigenous community. Many in Soluve are aware of the different TEK practices within Soluve, and most of these knowledges are still seen as important. Most people of Soluve do live in the village and therefore consider themselves as traditional, well-versed with their local knowledge.

On the other hand, while most of the knowledge are still practised within the community, the processes of globalization and industrialization have had some impacts on the community and the individuals within it. The results showed that while most participants knew about TEK and TEK practices, the elders of the community have more knowledge than those below 30 years of age. This might be a result of more young people moving out of the village to seek formal education in urban areas. All participants below 30 years of age seemed to lack some important knowledge of food production and food preservation in their community. One of the main participants in this research had moved away from the village at a very young age and spent little time with parents and grandparents. This participant therefore had little idea of some important food production and food preservation techniques. This participant was also an older member of the community, carrying a knowledge of the past no longer evident in practice and not known to most participants. People who have moved to Soluve have introduced new ways of doing things. These people are from either another tribe, island or province. Culture varies between many communities in the Solomon Islands, so some of the ways brought by outsiders may be new in Soluve. Many older people in the village have passed away, especially those who had much of the old knowledge. Because of this many are not able to pass knowledge onto the younger generation.

Shifting cultivation systems are said to be changing in the face of modern land use systems around the world. Most participants in Soluve highlighted the change in food cultivation in the village. Several participants in the community highlighted the fact that despite development changes in the Soluve community, shifting cultivation remained the main form of maintaining a reliable food supply, in turn providing a sustainable food supply. 
The data gathered in the research clearly indicated that older informants had the most in-depth traditional knowledge, thus underlining the potentially threatened state of TEK among the younger generation (Pollard et al, 2015). Agricultural landscapes have changed drastically in areas in Europe for thousands of years with changes in society and the agricultural revolution (Gomez-Baggethun, 2013). The adoption of new agricultural practices in Soluve is evident. In the past, sticks were used as a traditional farming implement to dig and cultivate soil, whereas now new tools such as knives, rakes and hoes are in use. The local people of North Western Patagonia maintained traditional farming practices - for instance, retaining the use of vegetable gardens - but they have also adopted the use of greenhouses to maintain the quality and control of their crops (Gomez-Baggethun, Corbera \& Reyes-Garcia, 2013).

Formal education has played an important role in cultural erosion. Education is said to be a driving force behind Pacific Islanders' increasing alienation from their island ecosystems and their cultural traditions in the villages. Globalization has influenced indigenous communities with the wave of technologies such as television, social media and movies. Thaman (2008) describes how youth no longer have the interest or time to put into acquiring traditional knowledge from their elders and so their cultural heritage is fading away. Reyes-Garcia et al (2013) also examines the way established schools have influenced the processes of learning from elders in communities. It was also interesting to note that a lot of the younger participants with higher levels of education have little knowledge of preservation techniques and TEK knowledge in general. It seemed that TEK was of little interest to several of them. For the people of Soluve, understanding and attaining the knowledge available from their immediate surroundings is a means of survival. Martin et al (2010) offer an important perspective on this, underlining why understanding TEK can help sustain this knowledge. As the author points out, "Rapid losses of language and culture make urgent the research of TEK and the aforementioned goal to respect, preserve and maintained traditional knowledge". This goes to show that sustaining TEK is important and the goal to preserve and respect TEK within indigenous communities is critical.

While many societies in the Solomon Islands have been exposed to the effects of development and urbanization, TEK has remained in many of the rural and urban areas 
in the Solomon Islands. This has been the case for the Soluve Community. According to most of the people interviewed in Soluve, traditional farming practices have certainly changed over the years and some are no longer practised by the people themselves. However, many of these participants also stated that although there have been changes, these have not been drastic and many traditional practices remain (Gomez- Baggethun, Corbera \& Reyes-Garcia, 2013). Traditional food preservation, such as that using the motu, for instance, is still practised. Food preparation, such as smoking fish on hots stones, is also still practised according to the traditional method. The traditional shifting cultivation is still commonly practised. Many in the community still have the traditional knowledge which they have always needed to survive. The practice of observation is widely used.

Veitayaki (2002) highlights the important of remembering traditional knowledge. He states: "The question for us then is whether we still remember enough of our indigenous knowledge, skill and experience to resume the relations our forefathers had with their surrounding" (Veitayaki, 2002). This research has shown how the people of Soluve have used traditional knowledge to assist in their food production to be more resilient in times of natural disasters. It showed that TEK is important for Melanesian countries facing the impacts from climate change. This research is important because it can contribute to the knowledge around TEK and resilient food production in the Solomon Islands. It is also important because few have been doing this research to date, while people can and ought to be made aware of the importance of TEK in a world heavily dependent upon modern science. The documentation of TEK in the Soluve community is vital and this can be used in further research. Indigenous researchers should be motivated to carry out further research in their own communities in order to understand the knowledge that is well-appreciated by the local people. 


\section{CHAPTER 5: CONCLUSION}

The Solomon Islands are vulnerable to natural disasters such as cyclones, flooding, droughts, earthquakes and tsunamis. The impact of climate change has been evident in low-lying areas such as in the Pacific Islands. Key findings from this research indicate that heavy rainfalls and flooding are the main disasters that have occurred in Soluve over the years. Drought was another major concern. Participants have stated that their gardens have been destroyed during these disasters and events. The community of Soluve have depended on their TEK for many years for their survival and livelihood. Food production is one aspect of their TEK still in practice. The flooding and rainfall have affected food production in Soluve. Emergency food such as sago, swamp taro and bananas are seen as emergency foods for times of disaster because they are readily available.

Methods of food production in Soluve included food cultivation and preservation techniques. Shifting cultivation has been around for many years and is part of food cultivation in Soluve and other parts of Melanesia. Shifting cultivation involves clearing a certain area of bush to plant crops and leaving it to fallow for a few years after harvesting. All members of the Soluve community have practised crop cultivation including children who have helped alongside their parents and grandparents. Food preservation is another method of food production in Soluve. Preserving food is a technique to enable certain foods to last longer through either cooking, smoking or drying. The main form of preservation by the people of Soluve is drying through the traditional earth ovens called motu.

The responses of the community of Soluve are to document and retain TEK within the community. Modern education has influenced the way TEK is represented in Soluve, therefore participants are saying the TEK needs to be retained. The importance of TEK in Soluve is highly appreciated by both men and women and by the younger people and older people alike. The reason to retain TEK in Soluve is because their livelihood and survival depend on it. Passing on the knowledge to the younger generation is vital 
in Soluve and women play an important role in passing down knowledge. Parents and grandparents also also involved in the passing down of knowledge through teaching and observations.

There have been many changes in TEK in Soluve. Cultural change in Soluve is evident, especially in food production. The research showed changes in the way food is now cooked. Many new methods are being introduced into Soluve. Food is often cooked in pots and pans and, as a result, does not last as long as food prepared according to traditional methods. Storing food in traditional baskets is often not practised nowadays. Food is nowstored in containers bought from shops. Changes in cultivation techniques have also changed. Sticks and stones used for gardening are now being replaced by tools such as knives, axes and rakes. Drivers of change in Soluve have resulted from several factors. Most importantly is the impact of urbanization and industrialization which has introduced a Western approach to doing things.

Formal education has had a tremendous impact on people in Soluve. Many of the young people are now in formal educational sectors and are losing some of the knowledge which their elders have taught them. Migrating to the mainland for education has also taken most people away from the villages. The results have shown that many educated young people lack some important knowledge around food preservation. Other drivers of change include intermarriages and the death of older people in the community.

While many changes in food production are evident in Soluve, many have argued that knowledge is not eroding but evolving. That means knowledge is changing but also adapting to its changing environment. It is also certain that some knowledge is lost but not all - some traditional knowledge is still widely applied in Soluve. Some Western practices around food production have been introduced, but people have also remained true to traditional practices. The Soluve community have introduced Western tools, but also used traditional methods.

The main results which could be summarized from this research are that the impacts of climate change are obvious, that they are happening, and that the people of Soluve have grown accustomed to these environmental changes because they have grown resilient to these disasters and their impacts. The way they have become resilient is through the accumulated knowledge of TEK within the community acquired over the 
years. TEK has enabled them to be more resilient and better able to cope with and use available resources to survive within their changing environment.

Another main finding is that many traditional food production techniques are still being practised in the Soluve community. Traditional practices such as shifting cultivation are still practised by all members of the community. Food preservation is also common preparation ahead of any disaster. Practices such as the traditional motu, burning and smoking are amongst the main forms of food preservation. It was also obvious from the research that while much traditional knowledge is still intact, much of the "old" knowledge is not fully known to the younger members of the community. While others believe that this knowledge is dynamic, measures must be taken to ensure that the knowledge is still passed onto the next generation for many years.

This research only depended on the responses of 10 participants. It would be of benefit if the research had more participants. Only half of the participants are elderly. It would be good to interview more old people, as this group has shown themselves to be holders of traditional knowledge. The language barrier was also a limitation to this research. Understanding different concepts have proven quite difficult for most participants. Limited information on the Solomon Islands with regards to TEK has also been a barrier to this research. Few researches have been carried out in the Solomon Islands themselves, and therefore much information was obtained from scholarly journals and reports. Another limitation has been the timing. Living in a small village with many chores to be done through the day meant that the participants had only limited amounts of time for interviews. Another limitation was the location of the community. Transportation by boat can be dangerous, so my travel was limited to a day with fine weather for boating.

There is a need for future research in this area. The importance of food security in the Solomon Islands is crucial. Retaining our cultural knowledge is also crucial. Little research has been carried out in this area and so more information should be out there for other students to access. Further research into whether the increasing impacts of wild pigs in the village are a result of climate change could be an interesting topic to look into. Furthermore, a part of the research I would love to see go further would be the documentation of traditional knowledge in the Solomon Islands and especially in the 
Western Solomon Islands. Another interesting topic to be researched would be the erosion and evolution of TEK in the Western province in relation to Christianity, given that the Western Solomon Islands were the first to be visited by Western missionaries. The research was limited to food production and did not cover fishing methods in Soluve. One participant highlighted some fishing practices which are no longer used but could serve for future research in the area.

The conclusions I can take away from this research is that TEK is an important part of society. It is the people's survival and many of the traditional practices are no longer practised. This research will help both the people of Soluve and readers understand and document TEK within Soluve in order to be more resilient in the future. These can be passed down through many generations to come. As a young woman from Soluve, and educated under the 'white man's' system of education, I feel that it is my duty to let readers know that I too have come to appreciate the knowledge I have 'ignored' for many years and hope that many will come to love it as much as I do now. Climate change impacts will always continue to be a problem in the Solomon Islands and it is the duty of indigenous people to help document this knowledge for future generations. 


\section{BIBLIOGRAPHY}

. Adger, W.N., K. Brown, and E.L. Tompkins, 2006. The Political Economy of Cross-Scale Networks in Resource Co-Management. Ecology and Society 10(2): 9. http://www.ecologyandsociety.org/vol10/iss2/art9/.

Alexander C, Bynum, N; Johnson, E; King, U; Mustonen, T; Neofotis, P; Oettle, N; Rosenzweig, C; Vyacheslav, C; Vicarelli, S; Waterhouse, J \& Weeks, B. (2011). Linking indigenous and scientific knowledge of climate change. Bioscience. Vol. 61 (6), pp. 477484. doi: 10. 1525/bio.2011.61.6.10.

Anette Reenberg \& Torben Birch-Thomsen \& Ole Mertz \& Bjarne Fog \& Sofus Christiansen. Human Ecology (2008) 36:807-819 DOI 10.1007/s10745-008-9199-9.

Aswani, S \& Hamilton, J. R. (2004). Integrating indigenous ecological and customary sea tenure with marine and social science for conservation for bumpheard parrot fish (Bolbometopon muricatum) in the Roviana Lagoon, Solomon Islands. Environmental Conservation. 31 (1):69-83. DOI: 10.1017/s037689290400116X.

Baines, G \& Hviding, E. (1992). Traditional Environmental Knowledge from the Marovo Area of the Solomon Islands. In M. Johnson (ed), Capturing Traditional Environmental Knowledge (pp.81-101). Dene Cultural Institute. CA

Barthel, S, Crumley, C.L \& Svedin, U. 2013. Biocultural Refugia: Combating the Erosion of Diversity in Landscapes of Food Production. Ecology and Society. 18 (4):71. DOI: http://dx.doi.org/10.5751/ES-06207-180471.

Bayliss-Smith,T, Hviding, E \& Whitmore, T. 2003. Rainforest Composition, and Histories of Human Disturbances in Solomon Islands. AMBIO: A Journal of the Human Environment, 32(5):346-352. DOI: http://dx.doi/10.1579/0044-7447-32.5.346. 
Bell \& Taylor. 2015. Building climate-resilient food systems for Pacific Islands. Penang, Malaysia: WorldFish. Program Report: 2015-15.

Berkes, F., 1993: Traditional ecological knowledge in perspective. Traditional Ecological Knowledge: Concepts and Cases, J.T. Inglis, Ed., Canadian Museum of Nature/International Development Research Centre, International Program on Traditional Ecological Knowledge International Development Research Centre, 1-9.

Berkes, Colding \& Folke, 2000. Rediscover of Traditional Ecological Knowledge as adaptive management. Ecological Applications. 10(5) pp1251- 1262.

Berkes, F., \& Turner, N. J. (2006). Knowledge, learning and the evolution of conservation practice for social-ecological system resilience. Human Ecology, 34(4), 479.

Berkes, F., \& Francis, T. (1999). Sacred Ecology- Traditional Ecological Knowledge and Resource Management, USA.Butler, J., Tawake, A., Skewes, T., Tawake, L., \& McGrath, V. (2012). Integrating traditional ecological knowledge and fisheries management in the Torres Strait, Australia: the catalytic role of turtles and dugong as cultural keystone species. Ecology and Society, 17(4).

Campbell, J. 2014. Development, global change and traditional food security in Pacific Islands Countries. Reg. Environment Change. DOI: 10.1007/s10113-014-0697-6.

Campbell, J. 2006. Traditional Disaster Reduction in Pacific Island communities. GNS Science Report 2006/38. Institute of Geological and Nuclear sciences, Wellington.

Calamia, M. A. (1999). A methodology for incorporating traditional ecological knowledge with geographic information systems for marine resource management in 
the Pacific. SPC Traditional Marine Resource Management and Knowledge Information Bulletin, 10, 2-12.

Chhabra, V and Haris, A.A. (2015). Climate Variability, Extreme Rainfall and Temperature Events over different Agro-ecological Zones of Bihar. Journal of AgriSearch 2(3): 189-194.

Church, J.A., P.U. Clark, A. Cazenave, J.M. Gregory, S. Jevrejeva, A. Levermann, M.A. Merrifield, G.A. Milne, R.S. Nerem, P.D. Nunn, A.J. Payne, W.T. Pfeffer, D. Stammer and A.S. Unnikrishnan, 2013: Sea Level Change. In: Climate Change 2013: The Physical Science Basis. Contribution of Working Group I to the Fifth Assessment Report of the Intergovernmental Panel on Climate Change [Stocker, T.F., D. Qin, G.-K. Plattner, M. Tignor, S.K. Allen, J. Boschung, A. Nauels, Y. Xia, V. Bex and P.M. Midgley (eds.)]. Cambridge University Press, Cambridge, United Kingdom and New York, NY, USA.

Clarke, W. C. (1990). Learning from the past: traditional knowledge and sustainable development. The Contemporary Pacific, 233-253.

Creswell, J. W. (2003). Research design. Qualitative, quantitative and mixed methods approaches, 2 .

Davis, A. \& Wagner, J.R. Human Ecology (2003) 31: 463. doi:10.1023/A:1025075923297

Drew, J. A. (2005). Use of traditional ecological knowledge in marine conservation. Conservation biology, 19(4), 1286-1293.

Dudgeon, R. C., \& Berkes, F. (2003). Local understandings of the land: Traditional Ecological Knowledge and indigenous knowledge. In Nature Across Cultures (pp. 75-96). Springer Netherlands. 
Englberger, et al. (2008). Carotenoid and mineral content of Micronesian giant swamp taro (Cyrtosperma) cultivars. Journal of food composition and analysis. Vol 21, pp. 93-106. Doi: 10.1016/j.jfca.2007.09.007.

Fazey L; Pettorelli, N; Kenter, J; Wagatora, D AND Schuett, D. (2011). Maladaptive trajectories of change in Makira, Solomon Islands. Global Environment Change, 21 (2011)1275-1289.

Fisher, B, B. (2011). Climate change and human security in Tuvalu. Global Change, Peace \& Security. 23:3, pp. 293-313. DOI: 10. 1080/14781158.2011.601852.

Fletcher S; Thiessen, J; Gero, A; Rumsey, M; Kuruppu, N and Willetts, J. (2013). Traditional Coping Strategies and Disaster Response: Examples from the South Pacific Region. Journal of Environmental and Public Health. 264503.

Folke, C. 2004. Traditional knowledge in social-ecological systems. Ecology and Society 9(3): 7. [online] URL: http://www.ecologyandsociety.org/vol9/iss3/art7/

Fry, G. (1997). Framing the Islands: Knowledge and Power in Changing Australian Images of" the South Pacific". The Contemporary Pacific, 305-344.

Gadgil, M., Berkes, F., \& Folke, C. (1993). Indigenous knowledge for biodiversity conservation. Ambio, 151-156.

Gomez-Baggethun. 2012. Traditional ecological knowledge and community resilience to environmental extremes: A case study in Doñana, SW Spain. Global Environmental Change. 22, 640-650.

Gomez-Baggethun. 2010. Traditional Ecological Knowledge Trends in the Transition to a Market Economy: Empirical Study in the Donana Natural Areas. Conservation Biology. Vol. 24, NO.3, 721-729. DOI: 10.1111/j.15231739.2009.01401.x. 
Gomez-Baggethun, Corbera \& Reyes-Garcia, 2013. Traditional Ecological Knowledge and Global Environmental Change: Research findings and policy implications. Ecology and Society. 18(4)72. http://dx.doi.org/10.5751/ES-06288180472.

Harrington, J.M. (2015). Traditional Ecological Knowledge: Practical Roles in Climate Change Adaptation and Conservation (Climate Change and its cause, effects and Prediction). Nova Science Publication Inc.

Houde, N. 2007. The six faces of traditional ecological knowledge: challenges and opportunities for Canadian co-management arrangements. Ecology and Society 12(2): 34. [online] URL: http://www.ecologyandsociety.org/vol12/iss2/art34/

Huntington, H. P. (2000), USING TRADITIONAL ECOLOGICAL KNOWLEDGE IN SCIENCE: METHODS AND APPLICATIONS. Ecological Applications, 10: 1270-1274. doi:10.1890/1051-0761(2000)010[1270:UTEKIS]2.0.CO;2.

Hviding, E. (2003). H. Selin (ed.), Nature Across Cultures: Views of Nature and the Environment in Non-Western Cultures, 245-275.

Inglis, J.T (Ed). (1993). Traditional Ecological Knowledge, concepts and cases. International development research center, Canada.

Janif, S. Z., P. D. Nunn, P. Geraghty, W. Aalbersberg, F. R. Thomas, and M. Camailakeba. 2016. Value of traditional oral narratives in building climate change resilience: insights from rural communities in Fiji. Ecology and Society. 21 (2) 7. http://dx.doi.org/10.5751/ES-08100-210207. 
Joe McCarter \& Michael C. Gavin (2014) In Situ Maintenance of Traditional Ecological Knowledge on Malekula Island, Vanuatu, Society \& Natural Resources, 27:11, 1115-1129, DOI: 10.1080/08941920.2014.905896.

Johnson, M. (1998). Lore: capturing traditional environmental knowledge. Diane Publishing.

Kimmerer, R. W. (2002). Weaving traditional ecological knowledge into biological education: a call to action. BioScience, 52(5), 432-438.

Kjeld Rasmussen, Wilhelm May, Thomas Birk, Melchior Mataki , Ole Mertz \& Douglas Yee (2009) Climate change on three Polynesian outliers in the Solomon Islands: Impacts, vulnerability and adaptation, Geografisk Tidsskrift-Danish Journal of Geography, 109:1, 1-13, DOI: 10.1080/00167223.2009.10649592

Lauer, M \& Aswani, S. (2009). Indigenous ecological knowledge as situated practices: Understanding fisher's knowledge in the Western Solomon Islands. American Anthropologist. Vol 111 (3), pp. 317- 329. DOI: 10. 1111/J.15481433.2009.01135.x.

Lefale, P. F. (2010). Ua 'afa le Aso Stormy weather today: traditional ecological knowledge of weather and climate. The Samoa experience. Climatic Change,100(2), 317-335.

Leonard, S; Parsons, M; Olawsky, K and Kofod, F. 2013. The role of culture and traditional knowledge in climate change adaptation: Insights from East Kimberly, Australia. Global Environment Change. $23 . \quad 623-632$. http://dx.doi.org/10.1016/j.gloenvcha.2013.02.012. 
Levin, 2015. Food Production, Environment and Culture in the Tropical Pacific: Evidence for prehistoric and historic plant cultivation in Pohnpei, Federal States of Micronesia. Oregon University.

Live and learn. $2015 . \quad$ Retrieved from http://www.livelearn.org/locations/solomon-islands

Mallikarjuna, K. 2013. Food Security and Climate Change. International Journal of Research in Applied Natural and Social Sciences (IJRANSS) Vol. 1, Issue 1, 45-52.

Martin, 2010. Traditional Ecological Knowledge (TEK): Ideas, inspiration and designs for ecological engineering. Ecological Engineering. 36. 839-849. DOI: 10.1016/J.ecoleng.2010.04.001.

McCarter \& Gavin. 2011. Perceptions of the value of traditional ecological knowledge to formal school curricula: opportunities and challenges from Malekula Island, Vanuatu. Journal of Ethnobiology and Ethnomedicine, 7:38 http://www.ethnobiomed.com/content/7/1/38.

McKinnon, J. M. (1972). Bilua changes: culture contact and its consequences, a study of the Bilua of Vella Lavella in the British Solomon Islands. Victoria University of Wellington.

McNamara, K.E \& Prasad, S. S. (2014). Coping with extreme weather: communities in Fiji and Vanuatu share their experience and knowledge. Climate Change. 123:121-132. DOI 10.1007/s10584-013-1047-2.

Morrison, R. J., Geraghty, P. A., \& Crowl, L. (Eds.). (1994). Science of Pacific Island Peoples: Education, language, patterns \& policy (Vol. 4). editorips@ usp. ac. fj. 
Murphy et al. 2016. Adapting to climate change in shifting landscapes of belief. Climatic Change. 134:101-114. DOI 10.1007/s10584-015-1498-8.

Nancy J. Turner , Łukasz Jakub Łuczaj , Paola Migliorini , Andrea Pieroni , Angelo Leandro Dreon, Linda Enrica Sacchetti \& Maurizio G. Paoletti (2011) Edible and Tended Wild Plants, Traditional Ecological Knowledge and Agroecology, Critical Reviews in Plant Sciences, 30:1-2, 198-225, DOI: 10.1080/07352689.2011.554492.

Nadasdy, P. (1999). The Politics of Tek: Power and the "Integration" of Knowledge. Arctic Anthropology, Vol. 36, No. 1/2. pp. 1-18. University of Wisconsin Press. Taken from http://www.jstor.org/stable/40316502

Nunn, P. D., Kumar, R., Matararaba, S., Ishimura, T., Seeto, J., Rayawa, S., Kuruyawa, S., Nasila, A., Oloni, B., Ram, A. R., Saunivalu, P., Singh, P. and Tegu, E. (2004), Early Lapita settlement site at Bourewa, southwest Viti Levu Island, Fiji. Archaeology in Oceania, 39: 139-143. doi:10.1002/j.1834-4453.2004.tb00571.x

Nunn, P. (2012). Disruption of coastal societies in Pacific Islands from rapid sea-level fall about AD 1300: new evidence from northen Viti Levu Island, Fiji. Journal of Coastal Conservation. Vol 16 (2), pp. 199-209. DOI 10.1007/s11852-010-0142-z

Ole Mertz, Thilde Bech Bruun, Bjarne Fog, Kjeld Rasmussen and Jytte Agergaard doi:10.1111/j.1467-9493.2010.00389

Pollard, E.J.M; Thaman, R; Brodie, G; \& Morrison, C. (2015). Threatened Biodiversity and Traditional Ecolgical Knowledge: Associated Beliefs, Customs and Uses of Herpetofauna among the A're A're on Malaita Island, Solomon Islands. Ethnobiology Letters. Vol 6 (1), pp. 99-110. DOI: 10.14237/EBL.6.1.2015.389. 
Rasalato, E, Maginnity, V \& Bruenschweila, J. (2010). Using local ecological knowledge to identify shark river habitats in Fiji (South Pacific). Environmental Conservation. And customary 37(1): 90-97.

Reyes-Garcia, V; Maximilien, G; Luz, A.C; Paneque-Galvez; Marcia, M.j; OrtaMartinez, M; Pino, and Rubio-Campillo, X. 2013. Evidence of traditional knowledge loss among a contemporary indigenous society. Evolution and Human Behaviour. 34. 249-257. http://dx.doi.org/10.1016/j.evolhumbehav.2013.03.002.

Ruddle, K \& Hviding, E. (1992). Marine Resource Management in the context of Customary Tenure. Marine Resource Economics. Vol 7, pp 249-273.

Sheppard, P; Walter, R \& Aswani, S. (2004). Oral Traditional and the creation of late prehistory in Roviana Lagoon, Solomon Islands. Records of the Australian Museum. 29: 123-132.

Smith, B \& Wandel, J. 2006. Adaptation, adaptive capacity and vulnerability. Global Environmental Change. 16. 282-292. D0I:10.1016/j.gloenvcha.2006.03.008.

Schwarz, A. M., Béné, C., Bennett, G., Boso, D., Hilly, Z., Paul, C., \& Andrew, N. (2011). Vulnerability and resilience of remote rural communities to shocks and global changes: Empirical analysis from Solomon Islands. Global Environmental Change, 21(3), 1128-1140.

Thaman, R.R; Puia, T; Tongabaea, W; Namona, A \& Fong, T. (2010). Marine biodiversity and ethno biodiversity of Bellona (Mungiki) Island, Solomon Islands. Singapore Journal of Tropical Geography. 31, pp. 70-84. Doi: 10.1111/j.14679493.00391. 
Thaman, R; R. (2008) Pacific Island agrobiodiversity and ethno biodiversity: A foundation for sustainable Pacific I0sland life, Biodiversity, 9:1-2, 102-110, DOI: $10.1080 / 14888386.2008 .9712895$.

Thaman, K. H. (2003). Decolonizing Pacific studies: Indigenous perspectives, knowledge, and wisdom in higher education. The Contemporary Pacific, 15(1), 1-17.

Thomas Birk (2014) Assessing vulnerability to climate change and socioeconomic stressors in the Reef Islands group, Solomon Islands, Geografisk Tidsskrift- Danish Journal of Geography, 114:1, 59-75, DOI: $10.1080 / 00167223.2013 .878228$

Turner, R. A., Cakacaka, A., Graham, N. A. J., Polunin, N. V. C., Pratchett, M. S., Stead, S. M., \& Wilson, S. K. (2007). Declining reliance on marine resources in remote South Pacific societies: ecological versus socio-economic drivers. Coral Reefs, 26(4), 997-1008.

Turner, J. N; Ignace, B. M \& Ignace, R. (2000). Traditional Ecological Knowledge and Wisdom of the Aboriginal Peoples in British Columbia. Ethical Applications. 10(5), pp. 1275-1287.

Usher, P. J. (2000). Traditional ecological knowledge in environmental assessment and management. Arctic, 183-193.

Veitayaki, J. (2002), Taking advantage of indigenous knowledge: the Fiji case. International Social Science Journal, 54: 395-402. doi:10.1111/1468-2451.00391

Vinyeta, K., Whyte, K., \& Lynn, K. (2016). Climate change through an intersectional lens: gendered vulnerability and resilience in indigenous communities in the United States. 
Whyte, K. 2013. On the role of traditional ecological knowledge as a collaborative concept: a philosophical study. Ecological Processes, 2:7. Retrieved from http://www.ecologicalprocesses.com/content/2/1/7

Woodley, E. (2002). Local and indigenous knowledge as an emergent property of complexity: A case study in the Solomon Islands (Doctoral dissertation, The University of Guelph).

Yen, D. E. 1974. The origins of subsistence agriculture in Oceania and the potentials for future tropical food crops. Econ Bot (1993) 47: 3. https://doi.org/10.1007/BF02862202. 


\section{APPENDIX 1: INTERVIEW SCHEDULE}

Using Traditional Ecological Knowledge (TEK)] to assist resilient food production in Soluve Community: Interview Questions

Brief outline of the project background (Chelcia)

Interview Questions:

1. Can you tell me about the ways food is produced in Soluve?

2. Can you tell me about the ways food is preserved for the long term in Soluve?

3. Who are the main food producers and what roles do they play?

4. What type of food do you preserve for times of natural disaster?

5. What methods do you use to prepare and preserve food?

6. Do you draw on TEK to prepare and preserve food?

7. How is TEK passed down from generations to generations?

8. Who is the knowledge passed down to?

9. How different is food production practice now than it was when you were young?

10. Do you think it's important to ensure that TEK is retained in Soluve? If so, why?

11. Do you draw on newer methods of food preservation?

12. What can be done to help retain TEK within the community?

13. Do you think TEK that you use is specific to Soluve community or are there other practices in other communities?

14. Is there wider applicability of Soluve practices in other communities/countries. 


\section{APPENDIX 2: ETHICS APPROVAL}

TE WHARE WÃNANGA O TE OPPOKO O TE IKA A MÄUI

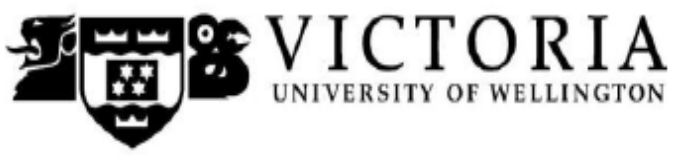

MEMORANDUM

Phone $\quad 0-4-4635205$

Email stephen.marshall@vuw.acnz

\begin{tabular}{l|l}
\hline TO & Chelcia Gomese \\
\hline COPY TO & \\
\hline FROM & Dr Stephen Marshall, Acting Convener, Human Ethics Committee \\
\hline DATE & 19 May 2016 \\
\hline PAGES & 1 \\
\hline SUBJECT & $\begin{array}{l}\text { Ethics Approval: 23079 } \\
\text { Using Traditional Ecological Knowledge to assist resilient food } \\
\text { production in Soluve Community }\end{array}$ \\
\hline
\end{tabular}

Thank you for your application for ethical approval, which has now been considered by the Standing Committee of the Human Ethics Committee.

Your application has been approved from the above date and this approval continues until 31 March 2017. If your data collection is not completed by this date you should apply to the Human Ethics Committee for an extension to this approval.

Best wishes with the research.

Stephen Marshall,

Acting Convener, Victoria University Human Ethics Committee 